\title{
MDP and other muropeptides - direct and synergistic effects on the immune system
}

\author{
Stephanie Traub ${ }^{1,2}$, Sonja von Aulock ${ }^{-1}$, Thomas Hartung ${ }^{1,2}$, Corinna Hermann ${ }^{1}$ \\ 'Biochemical Pharmacolog;, University of Konstanz, Konstanz, Germany \\ ${ }^{2}$ European Centre for the Validation of Alternative Methods, Joint Research Center, Ispra, Italy
}

\begin{abstract}
Muropeptides are breakdown products of peptidoglycan (PGN) of Gram-negative and Grampositive bacteria. They are released during bacterial growth and division, as part of the host response by lysozyme and amidases, or upon antibiotic treatment. After phagocytosis of bacteria or bacterial breakdown products by host immune cells, the muropeptides trigger intracellular signaling cascades, leading to altered gene expression and activation of the immune response. Numerous muropeptides and derivatives have been synthesized chemically to characterize their immunostimulatory effects and adjuvant activity. Muramyl dipeptide, a natural partial structure of PGN, is the minimal structure with adjuvant activity. This review discusses the structure and occurrence of muropeptides and gives a broad overview of their inflammatory and adjuvant activity and the possible involvement of receptors in these responses.
\end{abstract}

Keywords: Muropeptides, muramyl dipeptide, immune response, inflammation, adjuvant activity

\section{INTRODUCTION}

The recognition of conserved bacterial structures, so-called 'pathogen-associated molecular patterns' (PAMPs) by pattern recognition receptors (PRRs) is a prerequisite for the activation of anti-bacterial host defense reactions. The beststudied recognition pattern is lipopolysaccharide (LPS) of Gram-negative bacteria, which is located in the outer membrane and consists of a lipid A anchor, an inner oligosaccharide core and outer chains of variable repetitive carbohydrates. ${ }^{1}$ To a certain extent, lipoteichoic acid (LTA) represents the counterpart to LPS in Gram-positive bacteria. LTA is characterized by a polyol phosphate polymer anchored in the cytoplasmic membrane and projecting through the peptidoglycan (PGN). ${ }^{2-4}$ Gram-positive and Gram-negative bacteria both contain PGN, which consists of numerous glycan chains that are cross-linked by oligopeptides. These glycan chains are composed of alternating

Correspondence to: Dr Corinna Hermann, Biochemical Pharmacology, POB M655, University of Konstanz, 78457 Konstanz, Germany Tel: +49 7531884524 ; Fax: +497531884117 ;

E-mail: corinna.hermann@uni-konstanz.de
$N$-acetylglucosamine (GlcNAc) and $N$-acetylmuramic acid (MurNAc), with the amino acids coupled to the muramic acid. ${ }^{5,6}$ Muropeptides are breakdown products of PGN that bear at least the MurNAc moiety and one amino acid. One prominent muropeptide is muramyl dipeptide (MDP), which has been known since the 1970s to be the minimal structure that displays adjuvant activity?

PRRs on immune cells play a key role in the recognition and killing of invading bacteria. One prominent family of the PRRs is the Toll-like receptor (TLR) family. Up to now, 13 mammalian TLRs have been identified, 10 in humans and 12 in mice. ${ }^{\mathbf{8}-11}$ The extracellular domain of all TLR molecules contains leucine-rich repeats. The cytoplasmic Toll/interleukin-l receptor (TIR) domain shows similarities with a cytoplasmic domain of the interleukin-1 ( $\amalg-1)$ receptor family ${ }^{12}$ and was also found in the cytoplasmic protein MyD88 (myeloid differentiation factor 88$),{ }^{13}$ which functions as an ubiquitous adapter coupling TLR with lownstream signaling kinases. Recent data show that some TLRs also display MyD88-independent

Abbreviations: CpG-ODN, oligodeoxynucleotide containing cytosineguanosine; DAP, diaminopimelic acid; GlcNAc, $N$-acetylglucosamine; MDP, muramyl dipeptide; MurNAc, $N$-acetylmuramic acid; NOD, nucleotide-binding oligomerization domain; PBMCs, peripheral blood mononuclear cells; PGN, peptidoglycan; TLR, Toll-like receptor. 
pathways. ${ }^{14}$ TLR4 is required to induce a cytokine response to LPS, as shown in $\mathrm{C} 3 \mathrm{H} / \mathrm{HeJ}$ and C57BL/10ScCr mice, ${ }^{15}$ which carry spontaneous mutations of the $t l r^{4}$ genes, as well as in tlrt-knock-out mice. ${ }^{16} \mathrm{CD} 14$, an LPS receptor which lacks a membrane-spanning domain, and the extracellular adaptor molecules LPS-binding protein (LBP) $)^{17.18}$ and MD-2 19 are also involved in initiating the cellular response to LPS. The analysis of lipid A structures showed that variations in the molecular composition of lipid A led to either conical-shaped lipid A or cylindrical-shaped lipid A, which are recognized by TLR4 or TLR2, respectively. ${ }^{1,20}$

Although some investigators initially reported that LTA signaling is TLR4 dependent, ${ }^{21-23}$ several other groups have meanwhile proven that LTA recognition is instead TLR2-dependent. ${ }^{3,24-26}$ This was substantiated further by the receptor dependency of chemically synthesized LTA. ${ }^{27}$ The initially contradictory reports are likely due to the discrepant quality of the LTA preparations rather than to conformational variants. Commercial LTA preparations are often contaminated with endotoxin or other substances, ${ }^{28,29}$ and the immunostimulatory activity of LTA from Staphylococcus aureus is destroyed by hot phenol extraction ${ }^{4}$

Another potent activator of the immune system is bacterial DNA. Immune cells discriminate between host and bacterial DNA on the basis of unmethylated CPG motifs that occur more frequently in bacterial DNA than in vertebrate DNA. The recognition of bacterial DNA and synthetic $\mathrm{CpG}$ oligodesoxynucleotides (ODN), is mediated via TLR $9,{ }^{30}$ which is exclusively located intracellularly in the endoplasmic reticulum. ${ }^{31,32}$

Beside LPS, LTA and DNA, the dominant cell wall component PGN also possesses immune activating activity, inducing activation of transcription and release of inflammatory mediators. ${ }^{32-36}$ PGN was primarily thought to signal via TLR2. ${ }^{37-41}$ This is under controversial discussion at the moment, since recent publications have demonstrated that repurification of Gram-negative PGN preparations to elim inate lipoproteins and repurification of Gram-positive PGN to eliminate LTA both abolished the TLR2-dependent activity of PGN ${ }^{26,42}$ Our group extended these observations by showing that small quantities of LTA are indeed present in commercial PGN preparations and by demonstrating that these small quantities of LTA can account for the immunostimulatory potency of PGN preparations, because the cytokine-inducing activity of LTA is amplified by a factor of up to 1000 when it is presented to immune cells on a scaffold instead of in solution (Traub et al., submitted). This conclusion was further supported by the observation that a novel synthetic bisamphiphilic LTA, i.e. a model of two cross-linked LTA, displayed a greater immunostimulatory capacity than the monoamphiphilic molecule (Traub et al., submitted).
Recent reports have identified the cytoplasmic proteins NOD1 and NOD2 as receptors for PGN degradation products. The NOD proteins are subfamily members of the CATERPILLAR family. Prominent members of this subfamily are NOD1 (also called CARD4) and NOD2 (also called CARD15). Both are located in the cytoplasmic compartment and are characterized by three structural domains: (i) a C-terminal domain with multiple leucine-rich repeats (LRR) that recognizes microbial components; (ii) a central nucleotide binding site (NBS), which is important for self-oligomerization of the molecule; and (iii) N-terminal effector motifs, the CARD domains, one or two for NOD1 and NOD2, respectively. ${ }^{43} \mathrm{NODl}$ was shown to recognize a breakdown product of Gram-negative PGN, i.e. the dipeptide $\gamma$-Dglutamyl-meso-diaminopimelic acid (iE-DAP), of which the latter amino acid is not present in eukaryotes and is, therefore, an effective bacterial signature, ${ }^{44}$ while NOD2 recognizes $\mathrm{MDP},{ }^{45}$ a natural metabolite of both Grampositive and Gram-negative PGN.

In this review, we summarize the structure, occurrence and actions of MDP and other muropeptides on the immune system, their strong synergistic effect with other bacterial components as well as the receptors that may be responsible for their recognition and intracellular signaling.

\section{MUROPEPTIDES}

\section{Structure}

While Gram-negative bacteria possess only a thin layer of PGN (Escherichia coli l nm), Gram-positive bacteria bear a multilayered PGN cell wall (about $20-40 \mathrm{~nm}^{5}$ ), which encases the cytoplasmic membrane. Figure 1 shows the typical structure of the PGN of a Gram-negative bacterium (e.g. E. coli). PGN consists of a glycan backbone with altemating units of $N$-acetylglucosamine (GlcNAc) and $N$-acetylmuramic acid (MurNAc). Four to five amino acids are linked to the lactyl group of the MurNAc residue. The amino acids occur in alternating $\mathrm{L}$ - and D-isomers and include $\boldsymbol{\gamma}$-bonded D-glutamic acid, non-protein amino acids like diaminopimelic acid (DAP), omithine or lanthionine, in combinations typical for the bacterial species. These amino acids cross-link the glycan backbones, usually via the free amino group of a basic amino acid, such as L-lysine (Lys) or mesoDAP, for lys-type or DAP-type PGN, and a terminal amino acid with a free carboxy group, frequently D-alanine. ${ }^{46}$

The peptide structure of a Gram-negative bacterium like $E$. coli is commonly L-Ala- $\gamma$-D-Glu-meso-DAP-DAla-D-Ala, where the dibasic amino acid meso-DAP represents the cross-linking peptide. ${ }^{47}$ The typical structure of PGN of Gram-positive bacteria like $S$. aureus is L-Ala- $\gamma$-D-Glu-L-Lys-D-Ala-D-Ala, with an interpeptide 


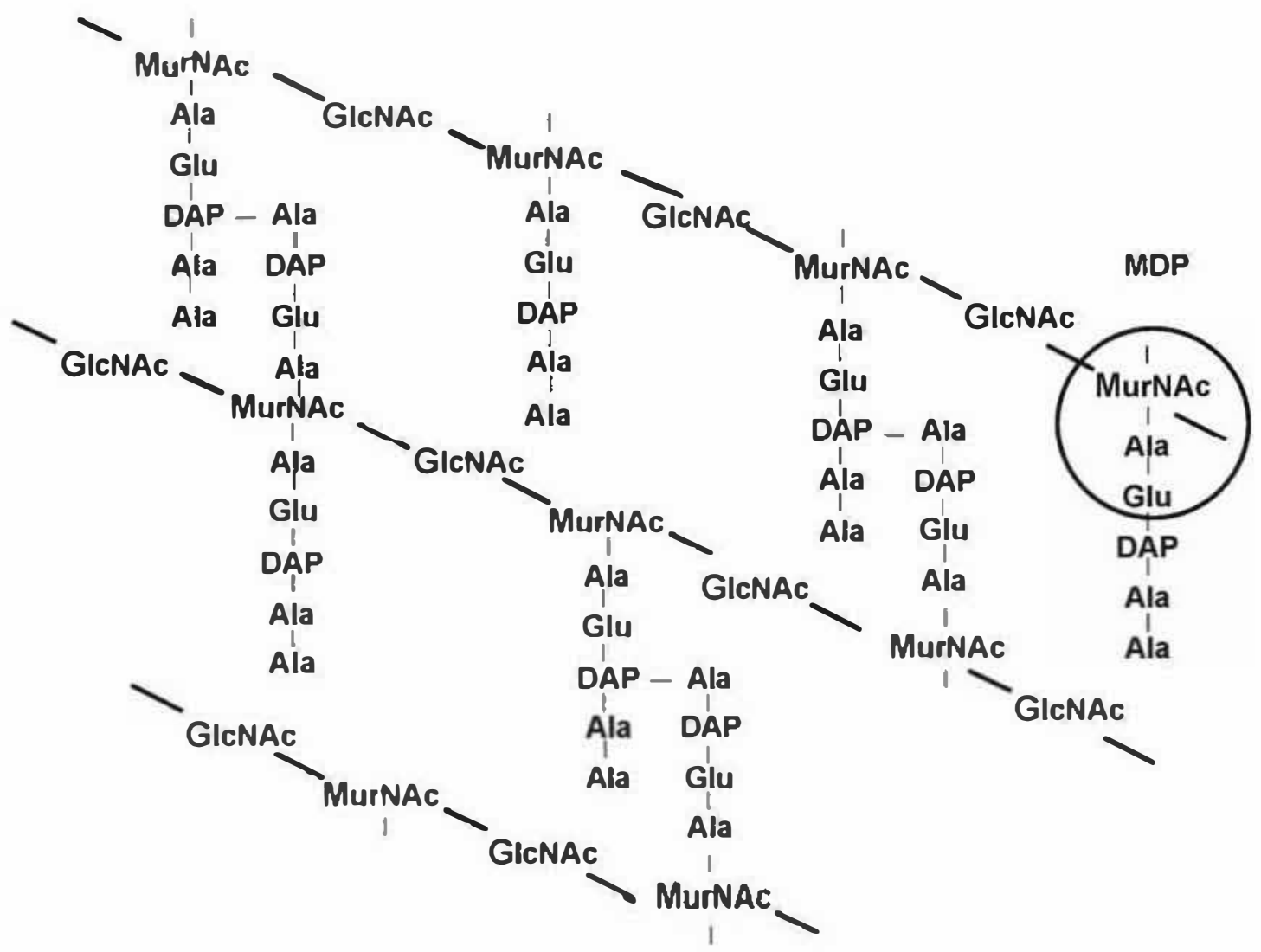

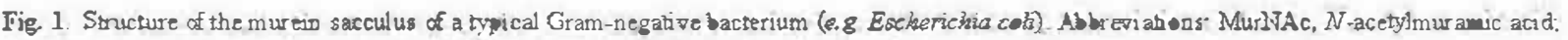
GlcN.Ac. N-acetylglucosanune, Ala, alanine. Glu. glutamate; DAP, diaminpimelic acid

bridge often made up of a chain of five Gly between the Lys side chain and the Ala of the neighboring chain. ${ }^{48}$ Further variations in the peptide chains can be found in both Gram-negative and Gram-positive PGNs. Usually, the amino acid, which is linked to the muramic acid, is L-Ala, but this can be replaced by Gly or L-Ser. The second position D-Glu can be replaced by midated Glu, Gly, amidated Gty or amidated Ala. The most conmon variations occur at position three, where mese-DAP or $\mathrm{L}$ Lys are the nam, but L-ornithine, LL-DAP, hydroxy-Lys and others may substitute. Position four and five are alrnost always occupied by D-Ala with very few variations. ${ }^{46}$ Additionally, there are variations of the interpeptide bridges. The interpeptide bridge can consist of a single amino acid, of homo-oligopeptides, wibich vary between two and six amino acids and are composed of Gly or L-Ala residues, or of hetero-oligopeptides made up of 2-7 amino acids with varions sequences. ${ }^{46}$ The well-known muropeptide MDP (N-acetyl-muranyl-L-alamyl-D-isoglutamine) corresponds to the stem peptide found in Streptececcus pnewmoniwe, Ala-isoGln-Lys-Ala-Ala, ${ }^{49}$ but in most other PGNs, Glu is found in the second position.

Muropeptides are released during bacterial growth and division. The activity of bacterial lytic transglycosylases mostly produces antry dromuropeptides, which cany the temninal MurNAc residue in the 1,6 antrydro-form. ${ }^{50}$ Lytic host enzymes like lysozyme and amidase can digest PGN, resulting in the release of muropeptide fragments. Muropeptides like the 1,6-anhydrodisaccharide tetrapeptide have been detected after cleavage of $E$. coli $P G N$ with amidase from hunan senm. ${ }^{\text {s1 }}$ When PGN from radiolabeled Bacilles subtilis cell walls was subjected to digestion by a macrophage cell line. disaccharides with di-, tri- and tetrapeptides (GlcNAc-MurNAcAla-isoGin-DAP-Ala and shortened forms) were released ${ }^{32}$ The PGN-hydrolases glucosaminidases also release nuropeptides, and endopeptidases like the PGN hy drolase lysostaphin produced by Sap/rylececcus sim wais, hydrolyze the peptide cross-bridges. ${ }^{33-55}$

The PGN recognition protein PGRP-L, which is mainly expressed in the liver, is an $\boldsymbol{N}$-acetylmuranoy /-Lalanine amidase that cleaves PGN between the sugar moiety and the peptide moiety. 56 This activity suggested a role of PGRP-L in initiating the irmate inumune response to PGN. However, Listeria monocytogenes also expresses an $N$-acetylrruramoyl-L-alanine amidase, which mainly releases peptidic chains and sugar moieties but not substantial amourits of muropeptides. ${ }^{57}$ Thus, the role of this kind of amidase may rather be to terminate inirnune reactions, not to trigger them. 


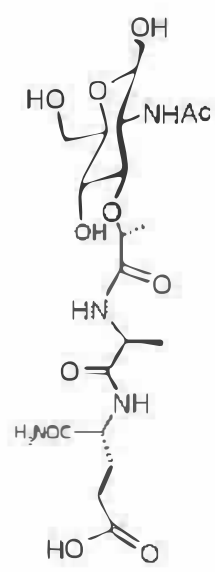

\section{MDP $M(A D i Q)$}

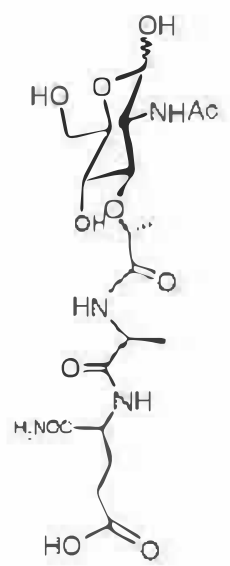

MDP-LL $M(A i Q)$

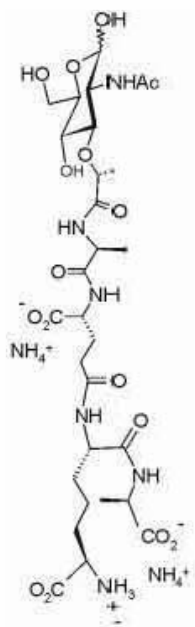

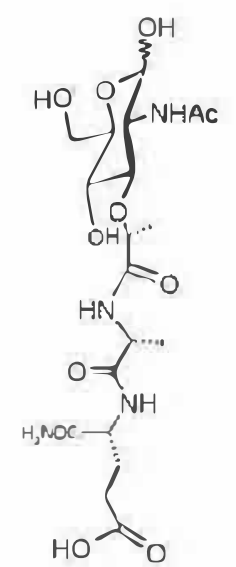

MDP-DD $M(D A D i Q)$

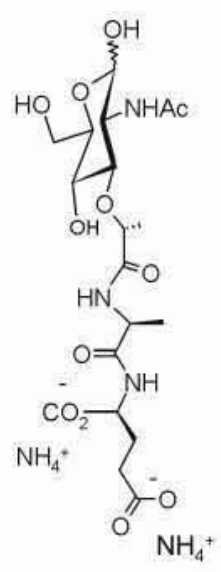

M(ADiE)

$M(A \gamma D E m D A P D A)$

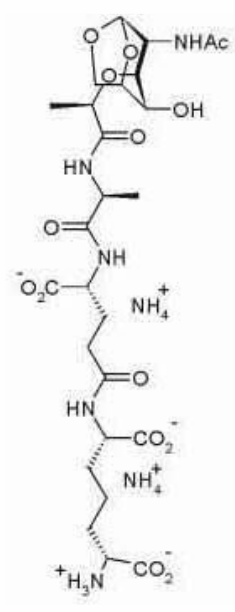

$A M(A \gamma D E m D A P)$

Fig. 2. Different murepeptide stnuctures. Abbreviations: M, $N$-acetylmuramic acid; $\mathbf{A M}, 1, \mathbf{6}$-anhydremuramic acid; $\mathbf{A}$, al anine; $\mathbf{D}$, amine acidin $\mathbf{D}$

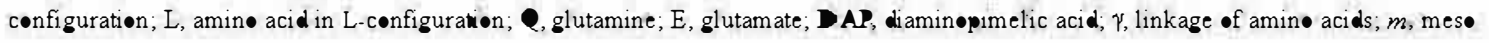

Taken together, a variety of muropeptides occur naturally, depending on the variability in PGN structure and dependent on the mode of PGN digestion. A selection of muropeptide structures is shown in Figure 2.

\section{Occurrence in tissue and body fluids}

To investigate whether free muropeptides occur naturally in host tissue and body fluids and to investigate their metabolism and clearance, muramic acid, which is not synthesized by mammalian enzymes, is a suitable marker for bacterial cell wall components. First evidence of muropeptides in tissue came from the discovery of sleep-promoting factor (factor $S$ ), later shown to be muropeptides, in cerebrospinal fluid of sleep-deprived healthy animals ${ }^{58}$ and in human urine from a healthy donor. ${ }^{59.61}$ No muramic acid could be found in brains and spleens of healthy rats, ${ }^{62,63}$ while in another study small amounts were detectable in liver, brain and kidney (100-150 pmol/g tissue) ${ }^{64}$ Higher muramic acid concentrations were detected in patient samples such as synovial fluid of septic patients $(<250-1700 \mathrm{ng} / \mathrm{ml})$, arthritic patients $(220-2000 \mathrm{ng} / \mathrm{ml})^{66}$ and in urine of patients with urinal tract infections (about $170 \mathrm{ng} / \mathrm{ml}$ ). ${ }^{6}$ In patients with pneurrococcal meningitis, muramic acid 
levels between 6.8 and $3890 \mathrm{ng} / \mathrm{ml}$ were detected in cerebrospinal fluid. ${ }^{3}$ Muramic acid in the intestinal content of healthy humans and in stool samples has been determined to lie in the range of $20-87 \mu \mathrm{mol} / 1 \mathrm{MDP}$ $(\sim 10-45 \mu \mathrm{g} / \mathrm{ml})$.8 To explain how bacterial breakdown products are taken up from the gut, Vavricka et al..8 recently hypothesized that the apical di/tri-peptide transporter $\mathrm{hPepTl}$ in the intestinal epithelium may transport MDP.

Muropeptides are highly water soluble and are, therefore, eliminated from the circulation rapidly. Larger, radiolabeled muropeptide structures like the disaccharide pentapeptide (GlcNAc-MurNAc-Ala-isoGln-mesoDAP-Ala-Ala) and other structures have been recovered in murine urine after intravenous administration. 69,70 After oral administration of $1.5 \mathrm{mg} / \mathrm{kg}$ MDP to rats, a maximal MDP concentration of $20 \mathrm{ng} / \mathrm{ml}(\sim .05 \%)$ was detected in the blood plasma after $1 \mathrm{~h}^{71}$ Two minutes after intravenous injection of the same dose of MDP into rats, less than $35 \%$ of the injected dose was detected; after $2 \mathrm{~h}, \mathrm{MDP}$ had nearly been eliminated ${ }^{71}$ Similar results were obtained in another study, where $2 \mathrm{mg}$ of MDP was injected into the ear vein of a rabbit.72

The investigation of the levels of muramic acid in healthy animals may be hampered by the limitations of the respective chromatographic methods used, which have detection limits in the nanogram per millilitre range. Measurements in infected animals and humans indicate the presence of muropeptides in diseased tissue. In most in vivo and in vitro studies reported so far, higher concentrations of MDP and other muropeptides (often $10-100 \mu \mathrm{g} / \mathrm{ml}$ ) have been used than were ever detected even in very sick patients (up to $4 \mu \mathrm{g} / \mathrm{ml}$ ), thus questioning the relevance of some of the results.

\section{Effects on the immune system}

In 1974, MDP was discovered as the minimal structure responsible for the improved reaction to mycobacteria in Freund's complete adjuvant. ${ }^{7}$ Since then, much effort has been made to isolate, synthesize and characterize the activity of MDP and other muropeptides. ${ }^{73,74}$ In this context, direct effects as well as priming and synergistic properties of muropeptides were discovered and researched independently of the studies on adjuvant activity, although the mechanisms of these activities appears to be at least partially inter-related. In the following, we shall discuss the vaccine adjuvant effects of muropeptides separately from the direct effects and the priming effects, in which pretreament with muropeptides augments immune responses to a later challenge, and synergistic effects, in which concentrations of muropeptides that are ineffective alone combine to induce a strong host response.

\section{Direct effects}

Numerous reports suggest that MDP and other muropeptides directly induce cytokines, thus activating and modulating immune responses and inflammation. However, these reports are controversial and seem to depend on the cell-type and species. For example, in the human Monomac- 6 cell line, MDP was reported to induce a weak induction of TNF- $\boldsymbol{\kappa}$ mRNA but not protein, ${ }^{75}$ while in human monocytic OCT-differentiated THP-1 and U937 cells induction of IL- 8 protein was observed in response to MDP. ${ }^{22}$ For human primary cells, IL-1 $\beta$ and TNF- $\boldsymbol{\alpha}$ release from in vitro MDP-stimulated monocytes has been shown; ${ }^{76,77}$ some authors suggest that activation of the inflammasome complex (caspase-activating complex $)^{7 \mathbf{8}, 79}$ is responsible for this activity. In contrast, we and others have reported no cytokine release from human whole blood or isolated monocytes by MDP or related compounds. ${ }^{\mathbf{2 0}, \mathbf{2 1}}$ Susceptibility towards in vitro MDP stimulation has been shown for macrophages from guinea pigs, rats and mice. ${ }^{22-4}$ Possible explanations for the controversial results could be different origin and purity of muropeptides, lack of exclusion of contamination (e.g. with the strong immune activator LPS), as well as use of often unphysiologically high MDP concentrations.

Although in vivo, mice are rather insensitive to muropeptides $\left(\mathrm{LD}_{5 \bullet}, 2200 \mathrm{mg} / \mathrm{kg}\right.$ i.p. $\left.{ }^{20}\right),{ }^{25} \mathrm{MDP}$ is considered to enhance non-specific resistance of the immune system. This has been proven in several in vivo models, where MDP stimulation decreased survival of intracellular Salmonella typhimurium, ${ }^{\text {n }}$ stimulated host resistance against Klebsiella pneumoniae $e^{\mathbf{s z}}$ and Candida albicans infections ${ }^{29}$ as well as killing of Leishmania donovani."

As mentioned above, MDP has been discovered to be a sleep-promoting factor in the 1970s. ${ }^{\circ}$ The somnogenic and sleep regulatory properties of MDP and derivatives have been demonstrated by transfer experiments, in which substances isolated from sleep-deprived animals induced sleep in the receiver animal. ${ }^{5,59,91}$ This might be explained by an indirect action of muropeptides via the induction of endogenous pyrogens like IL-1, TNF and No, which are probable sleep factors and might, therefore, play a role in sleep regulation. ${ }^{2-9}$ Furthermore, MDP and related muropeptides have been shown to induce some behavioral changes like hyperthermia, 9 hypermetabolism, weight loss and suppression of food intake during bacterial infection. "However, in order to reduce food intake, very high doses of $\mathrm{MDP}(>1 \mathrm{mg} / \mathrm{kg})$ were necessary." There is some evidence that, again, MDP may rather act indirectly via cytokines than having direct anorectic effects. ${ }^{96, \boldsymbol{*}, \boldsymbol{9}}$

To determine the receptor-dependence of the anorectic effect, the role of CD14, TLR2 or TLR4 has been investigated. MDP reduced food intake in wild-type mice of all respective genotypes, also in TLR4 deficient mice, 
Table 1. Synergy of LPS or lipid A with MDP and other muropeptides

\begin{tabular}{|c|c|c|c|c|c|}
\hline Model & $\begin{array}{l}\text { Stimulus } \\
\text { (concentration) }\end{array}$ & $\begin{array}{l}\text { Muropeptide } \\
\text { (concentration) }\end{array}$ & End-point & Synergy & Reference \\
\hline Human whole blood & $\begin{array}{l}\text { LPS, E. coli } 26: \mathrm{B} 7 \\
(10 \mathrm{ng} / \mathrm{ml})\end{array}$ & $\operatorname{MDP}(1 \mu \mathrm{g} / \mathrm{ml})$ & $\begin{array}{l}\text { TNF } \\
\text { IL-6 } \\
\text { IL-10 }\end{array}$ & $\begin{array}{l}\text { 3-fold } \\
2 \text {-fold } \\
-\end{array}$ & 80,124 \\
\hline Human whole blood (20\%) & $\begin{array}{l}\text { LPS, S. abortus equi } \\
(10 \mathrm{pg}-100 \mu \mathrm{g} / \mathrm{ml}\end{array}$ & $\operatorname{MDP}(10 \mathrm{ng} / \mathrm{ml})$ & $\begin{array}{l}\text { TNF } \\
\text { IL-1 } 1 \beta \\
\text { IL-6 } \\
\text { IL-10 }\end{array}$ & $\begin{array}{l}400 \text {-fold } \\
300 \text {-fold } \\
7 \text {-fold } \\
3 \text {-fold }\end{array}$ & 81 \\
\hline PBMCs & $\begin{array}{l}\text { LPS, } E \text {. coli } 111: \mathbf{B} 4 \\
(10 \mathrm{pg} / \mathrm{ml})\end{array}$ & $\operatorname{MDP}(1-100 \mathrm{ng} / \mathrm{ml})$ & $\begin{array}{l}\text { IL-ra } \\
\text { IL-1 } \\
\text { TNF }\end{array}$ & $\begin{array}{l}\text { 10-fold } \\
5 \text {-fold } \\
\pm\end{array}$ & 125 \\
\hline hu MDM & $\begin{array}{l}\text { LPS, } E \text {. coli } 111: B 4 \\
(10-100 \mathrm{ng} / \mathrm{ml})\end{array}$ & $\operatorname{MDP}(10 \mu \mathrm{g} / \mathrm{ml})$ & $\begin{array}{l}\text { IL-1 } \beta \text { mRNA } \\
\text { HLA-DR mRNA }\end{array}$ & $\begin{array}{l}+ \\
+\end{array}$ & 127 \\
\hline Isolated monocytes & $\begin{array}{l}\text { LPS, S. abortus equi } \\
(100 \mathrm{pg} / \mathrm{ml})\end{array}$ & $\operatorname{MDP}(10 \mathrm{ng} / \mathrm{ml})$ & TNF & 2 -fold & 81 \\
\hline Mononuclear cells (MNCs) & LPS, E. coli $(1 \mathrm{ng} / \mathrm{ml})$ & $\operatorname{MDP}(10 \mu \mathrm{g} / \mathrm{ml}$ & TNF & 2 -fold & 126 \\
\hline Monomac- 6 & $\begin{array}{l}\text { LPS, E. coli } \bullet 55: \mathrm{B} 5 \\
(30 \mathrm{ng} / \mathrm{ml})\end{array}$ & $\begin{array}{l}\text { MDP }(30 \mathrm{~min} \text { pre- } \\
\text { incubation; } 100 \mu \mathrm{g} / \mathrm{ml})\end{array}$ & $\begin{array}{l}\text { TNF } \\
\text { TNF mRNA }\end{array}$ & 2 fold additive & e 75 \\
\hline -CT-diff. THP-1 & $\begin{array}{l}\text { LPS, S. abortus equi } \\
(1-100 \mathrm{ng} / \mathrm{ml})\end{array}$ & $\operatorname{MDP}(1-100 \mathrm{ng} / \mathrm{ml})$ & IL-8 & 8 -fold & 22 \\
\hline ๑CT-diff. U937 & $\begin{array}{l}\text { LPS, S. abortus equi } \\
(0.1-10 \mathrm{ng} / \mathrm{ml})\end{array}$ & $\operatorname{MDP}(0.1-10 \mathrm{ng} / \mathrm{ml})$ & IL-8 & 3 -fold & 22 \\
\hline Rat in vivo & $\begin{array}{l}\text { LPS }, E \text {. coli } 111: B 4 \\
(25 \mu \mathrm{g} / \mathrm{kg})\end{array}$ & MDP (0.4 mg/kg) & Anorexia & + & 130 \\
\hline Rat liver macrophages & $\begin{array}{l}\text { LPS, E. coli } 127: B 8 \\
(5 \mathrm{ng} / \text { well })\end{array}$ & $\operatorname{MDP}(5 \mu \mathrm{g} /$ well $)$ & $\begin{array}{l}\text { Macrophage- } \\
\text { mediated cytolysis }\end{array}$ & $2-3$-fold & 128 \\
\hline RAW264.7 cells & $\begin{array}{l}\text { LPS, } E \text {. coli } \\
(10 \mathrm{ng}-1 \mu \mathrm{g} / \mathrm{ml})\end{array}$ & $\begin{array}{l}\text { MDP } \\
(40 \mathrm{ng}-25 \mu \mathrm{g} / \mathrm{ml})\end{array}$ & TNF & 3-10-fold & 129 \\
\hline Human whole blood (20\%) & $\begin{array}{l}\text { LPS, S. abortus equi } \\
(100 \mathrm{pg} / \mathrm{ml})\end{array}$ & $\begin{array}{l}\text { MurNAc-Ala } \\
\text { GMDP } \\
\text { MurNAc-Ala-Gln } \\
\text { MurNAc-Ala-Gln-Lys } \\
\text { MDP (DD) } \\
\text { MDP (LL) } \\
(10 \mathrm{ng} / \mathrm{ml})\end{array}$ & TNF & $\begin{array}{l}1.3 \text {-fold } \\
5 \text {-fold } \\
4 \text {-fold } \\
3 \text {-fold } \\
- \\
-\end{array}$ & 81 \\
\hline -CT-diff THP-1 & $\begin{array}{l}\text { Lipid A, E. coli } \\
\text { (LA-15-PP) } \\
(1-100 \mathrm{ng} / \mathrm{ml})\end{array}$ & $\begin{array}{l}\text { MDP } \\
\text { FK } 156 \\
\text { FK } 565 \\
\text { iE-DAP } \\
(1-100 \mu \mathrm{g} / \mathrm{ml})\end{array}$ & IL-8 & $\begin{array}{l}5 \text {-fold } \\
7 \text {-fold } \\
\text { Similar (ns) } \\
-\end{array}$ & 132 \\
\hline $\mathrm{BMDM}\left(\mathrm{N} \bullet \mathrm{D} 1^{-1-}\right)$ & $\begin{array}{l}\text { LPS, S. typhimurium } \\
(100 \mathrm{ng} / \mathrm{ml})\end{array}$ & $\begin{array}{l}\text { iE-DAP } \\
1 \mathrm{ng} / \mathrm{ml} \\
1 \mu \mathrm{g} / \mathrm{ml}\end{array}$ & IL-6 & $\begin{array}{l}100 \text {-fold } \\
500 \text {-fold }\end{array}$ & 44 \\
\hline $\begin{array}{l}\text { HTE derived from } \\
\text { hamster racheal issue }\end{array}$ & $\begin{array}{l}\text { LPS, } \\
\text { E. coli } \\
(100 \mathrm{EU} / \mathrm{ml} ; \\
1-10000 \mathrm{EU} / \mathrm{ml})\end{array}$ & TCT & $\begin{array}{l}\text { IL-1 } \boldsymbol{\kappa} \\
\text { IL-1 amRNA } \\
\text { No } \\
\text { Inhibition of DNA } \\
\text { synthesis }\end{array}$ & $\begin{array}{l}5.5 \text { fold } \\
+ \\
2-\text { fold }\end{array}$ & $80 \%$ \\
\hline
\end{tabular}


thus indicating that this effect does not stem from possible LPS contamination. The anorectic effect of MDP was blunted in CD14- and TLR2-knockout mice, indicating that CD14 and TLR2 are involved in the signaling pathway of MDP-induced anorexia. ${ }^{100}$

In addition to muropeptide effects like immune activation or anorexia, which have been studied in greater detail (although far from being completely understood), many diverse effects, like induction of leukocytosis, protein influx into cerebrospinal fluid or brain edema in a rabbit model of meningitis ${ }^{101}$ have been described. In renal cells, muropeptides have been shown to induce apoptosis ${ }^{102}$ and a recent publication suggests that this is mediated via calreticulin, ${ }^{103}$ which has also shown to be a binding protein for MDP and PGN. ${ }^{104}$

\section{Adjuvant activity}

As an immunogenic adjuvant, MDP increases phagocytic and anti-microbial activity ${ }^{105,106}$ by enhancing the expression of surface markers that are involved in cellular adhesion processes and co-stimulation for antigen presentation. ${ }^{107,108}$ In addition, MDP enhances antigen processing and presentation by antigen-presenting cells, thereby leading to increased antibody-mediated cytotoxicity, ${ }^{109}$ which thus improves the induction of antibodies by vaccine antigens. ${ }^{110,111}$ Furthermore, MDP as well as other muropeptides (ripeptides and disaccharide tri- and tetrapeptides) induce cellular immune defenses, as evidenced by delayed-type hypersensitivity skin reactions. ${ }^{7112} \mathrm{MDP}$ has been shown to augment the effect of other immunomodulators like IFN- $\gamma^{113}$ and to synergize with cytokines to stimulate the differentiation and proliferation of lymphocytes. ${ }^{114}$

\section{Priming effects}

Muropeptides prime for enhanced susceptibility of animals towards anaphylactic reactions and lethal toxicity in response to bacterial endotoxins. ${ }^{115}$ LPS species of low toxicity were found to lead to anaphylactic reactions and reactions to high-toxicity LPS were further augmented ${ }^{35}$ The priming ability of MDP occurred in endotoxin-sensitive and -resistant strains like $\mathrm{C} 3 \mathrm{H} / \mathrm{HeJ}$ mice, but variations were observed among different mouse strains; for example, $\mathrm{C} 3 \mathrm{H} / \mathrm{HeN}$ mice are highly and C57BL/6 are less susceptible. ${ }^{116}$ To achieve optimal priming effects, distinct time schedules ( $4 \mathrm{~h}$ before and after administration of LPS $^{16-118}$ and administration routes (intravenous or intraperitoneal injection) of MDP must be followed. ${ }^{116}$

Structural requirements of muropeptides to prime for induction of anaphylactic reactions by LPS have been investigated in $\mathrm{C} 3 \mathrm{H} / \mathrm{HeJ}$ mice using the priming conditions mentioned above. While the DAP-type muropeptide GlcNAc-MurNAc-pentapeptide induced no anaphylactic reactions, the disaccharide-tetrapeptide and the MurNAc-terapeptide showed marginal reactions, but the disaccharide-tripeptide and the MurNAc-tripeptide led to death of the animals. ${ }^{119} \mathrm{MDP}$ analogues, in which the Disoglutamine residue of MDP was replaced by D-glutamine, D-glutamic acid or D-isoasparagine, showed lesser priming than $\mathrm{MDP}$, and $\mathrm{MDP}$ analogues with replacement of L-glutamic acid, L-glutamine or L-isoglutamine were inactive. ${ }^{11}$ Furthermore, a synthetic lactyl peptide (desmuramylpeptide) D-lactyl-L-Ala- $\gamma$-D-Glu-meso-DAP-Gly (FK156) also exhibited priming activity for anaphylactic reactions. ${ }^{11}$ Thus, MDP is the minimal structure for priming effects; other structures are also effective, but apparently not fragments that are larger than the disaccharideterapeptide. These observations are in line with a recent publication, which shows that in mice defective for the protein NOD2 (recently identified as the MDP receptor), endotoxic shock induce by pre-reament with MDP was prevented ${ }^{120}$ As a mechanism for the anaphylactic reaction, a complement-dependent degradation of platelets, which have accumulated in liver and lung, resulting in acute inflammation with severe tissue destruction has been suggested. ${ }^{121-123}$

\section{Synergistic effects with LPS}

$\mathrm{MDP}$ and other muropeptides are strong immune amplifiers. In contrast to priming effects, where one stimulus is administere before the second stimulus, synergism is defined as a situation in which the combination of two weak stimuli, leads to an enhanced response. Synergistic actions of MDP and LPS have been described in many studies using different cell types and stimulus concentrations. Although different end-points, mostly cytokines, have been measured, all studies consistently describe srong synergistic effects of LPS and muropeptides. Table 1 gives an overview of these studies with regard to cellular models, stimulus concentrations and end-points. Synergistic results were obtained in vitro with human primary cells like whole blood, ${ }^{\boldsymbol{n}, \mathbf{8 1}, 124} \mathrm{PBMCs},{ }^{125}$ isolated monocytes, ${ }^{125-127}$ and various human monocytic $^{22,127}$ and rodent cell lines ${ }^{128,129}$ as well as in vivo in a rat model of anorexia. ${ }^{13}$ Only a few studies have investigated mRNA levels, but have shown for TNF- $\boldsymbol{\alpha}$ and IL$1 \boldsymbol{\alpha}$ that the LPS/muropeptide synergism already affected the mRNA level $1^{75,81}$ and experiments using actinomycin $\mathrm{D}$ demonstrated that this effect is due to increased de novo transcription, rather than to an increase in mRNA stability. ${ }^{\text {s1 }}$ Several studies have extended these investigations from MDP to further muropeptides with different structures, which were extracted and purified or synthesized, and have defined structural prerequisites and minimal active structures. ${ }^{44, \boldsymbol{z} 1,131,132}$

\section{Synergistic effects with other TLR agonists}

Muropeptides exert remarkable priming and synergistic effects with the TLR4 agonists LPS or lipid A. These 
Table 2. Synergy of different stimuli with MDP and other muropeptides

\begin{tabular}{|c|c|c|c|c|c|c|}
\hline Receptor & $\begin{array}{l}\text { Stimulus } \\
\text { (concentration) }\end{array}$ & $\begin{array}{l}\text { Muropeptide } \\
\text { (concentration) }\end{array}$ & End-point & Synergy & Model & Ref. \\
\hline TLR2 & LTA, S. aureus $(0.1-10 \mu \mathrm{g} / \mathrm{ml})$ & $\operatorname{MDP}(1-100 \mu \mathrm{g} / \mathrm{ml})$ & IL-8 & 7 -fold & OCT-diff. THP-1 & 22 \\
\hline TLR2 & $\begin{array}{l}\text { LTA, S. aureus }(0.1 \mu \mathrm{g} / \mathrm{ml}) \\
\text { LTA, B. subtilis }(0.1 \mu \mathrm{g} / \mathrm{ml})\end{array}$ & $\begin{array}{l}\text { GMDP } \\
\text { MDP } \\
\text { MDP (LL) } \\
\text { MDP (DD) } \\
\text { GMDP } \\
(1 \mu \mathrm{g} / \mathrm{ml}, 10 \mu \mathrm{g} / \mathrm{ml})\end{array}$ & N• & $\begin{array}{l}2 \text {-fold } \\
2 \text {-fold } \\
1.5 \text { fold } \\
- \\
3 \text {-fold }\end{array}$ & $\mathrm{J} 774.2$ & 134 \\
\hline TLR2 & LTA, S. aureus $(100 \mathrm{ng} / \mathrm{ml})$ & $\operatorname{MDP}(10 \mathrm{ng} / \mathrm{ml})$ & TNF & - & $\begin{array}{l}\text { Human whole } \\
\text { blood }(20 \%)\end{array}$ & $\begin{array}{c}\text { See } \\
\text { Fig. } 3\end{array}$ \\
\hline TLR2 & LTA, S. aureus $(10 \mu \mathrm{g} / \mathrm{ml})$ & $\operatorname{MDP}(50 \mathrm{ng} / \mathrm{ml})$ & TNF & - & $\begin{array}{l}\text { PBMCs } \\
(10 \% \text { serum })\end{array}$ & $\begin{array}{l}\text { Unpub. } \\
\text { observ. }\end{array}$ \\
\hline TLR2 & LTA, S. aureus $(10 \mu \mathrm{g} / \mathrm{ml})$ & $\operatorname{MDP}(50 \mathrm{ng} / \mathrm{ml})$ & TNF & 5-fold & $\begin{array}{l}\mathrm{PBMCs} \\
\text { (without serum) }\end{array}$ & $\begin{array}{c}\text { See } \\
\text { Fig. } 3\end{array}$ \\
\hline TLR2 & $\begin{array}{l}\text { LTA, S. aureus } \\
\text { S. pneumoniae } \\
(0.04-1 \mu \mathrm{g} / \mathrm{ml})\end{array}$ & $\begin{array}{l}\text { MDP }(30 \mathrm{~min} \\
\text { preincubation; } 100 \mathrm{ng} / \mathrm{ml})\end{array}$ & TNF & $\begin{array}{l}5 \text {-fold } \\
5 \text {-fold }\end{array}$ & $\begin{array}{l}\text { Human monocytes } \\
(2.5 \% \text { serum })\end{array}$ & 133 \\
\hline TLR2 & MALP-2 $(10 \mathrm{ng} / \mathrm{ml})$ & $\operatorname{MDP}(50 \mathrm{ng} / \mathrm{ml})$ & TNF & 5-fold & $\begin{array}{l}\text { PBMCs } \\
\text { (without serum) }\end{array}$ & $\begin{array}{l}\text { See } \\
\text { Fig. } 3\end{array}$ \\
\hline TLR2 & MALP-2 $(1 \mu \mathrm{g} / 1)$ & $\operatorname{MDP}(20 \mu \mathrm{g} / \mathrm{l})$ & $\begin{array}{l}\text { TNF } \\
\text { IL-1 }\end{array}$ & $\begin{array}{l}2.1 \text {-fold } \\
3.5 \text {-fold }\end{array}$ & PBMCs & 135 \\
\hline$\overline{\text { TLR2 }}$ & MALP-2 $(1 \mu \mathrm{g} / \mathrm{ml})$ & $\operatorname{MDP}(10 \mu \mathrm{g} / \mathrm{ml})$ & $\begin{array}{l}\text { TNF } \\
\text { IL-1 } \\
\text { IL-10 }\end{array}$ & $\begin{array}{l}2 \text {-fold } \\
6 \text {-fold } \\
6 \text {-fold }\end{array}$ & MNCs & 126 \\
\hline$\overline{\text { TLR2 }}$ & PGN $(100 \mu \mathrm{g} / \mathrm{ml})$ & $\begin{array}{l}\text { MDP ( } 30 \mathrm{~min} \text { pre- } \\
\text { incubation; } 100 \mu \mathrm{g} / \mathrm{ml}\end{array}$ & $\begin{array}{l}\text { TNF } \\
\text { TNFmRNA }\end{array}$ & $\begin{array}{l}\text { 2-fold } \\
\text { additive }\end{array}$ & Monomac-6 & 75 \\
\hline TLR2 & $\operatorname{Pam}_{3}$ Cys $(1-100 \mathrm{pg} / \mathrm{ml})$ & $\begin{array}{l}\text { MDP } \\
\text { FK } 156 \\
\text { FK } 565 \\
(1-100 \mu \mathrm{g} / \mathrm{ml})\end{array}$ & IL-8 & $\begin{array}{l}\text { 4-fold } \\
\text { 4-fold } \\
\text { Similar (data } \\
\text { not shown) }\end{array}$ & -CT-diff. THP-1 & 132 \\
\hline TLR2 & $\operatorname{Pam}_{3}$ Cys $(1 \mu \mathrm{g} / \mathrm{ml})$ & $\operatorname{MDP}(10 \mu \mathrm{g} / \mathrm{ml})$ & $\begin{array}{l}\text { TNF } \\
\text { IL-1 } \\
\text { IL-10 }\end{array}$ & $\begin{array}{l}2 \text {-fold } \\
8 \text {-fold } \\
6 \text {-fold }\end{array}$ & $\mathrm{MNCs}$ & 126 \\
\hline TLR2 & $\operatorname{Pam}_{3}$ Cys $(10 \mu \mathrm{g} / \mathrm{l})$ & $\operatorname{MDP}(20 \mu \mathrm{g} / \mathrm{l})$ & $\begin{array}{l}\text { TNF } \\
\text { IL-1 } 1 \beta\end{array}$ & $\begin{array}{l}1.8 \text {-fold } \\
3.2 \text {-fold }\end{array}$ & PBMCs & 135 \\
\hline TLR2 & $\operatorname{Pam}_{3} \operatorname{Cys}(2 \mu \mathrm{g} / \mathrm{ml})$ & $\operatorname{MDP}(1,10 \mu \mathrm{g} / \mathrm{ml})$ & IL-6 & 2 -fold & BMDM & 120 \\
\hline TLR3 & Poly(I:C) $(50 \mu \mathrm{g} / \mathrm{ml})$ & $\operatorname{MDP}(10 \mu \mathrm{g} / \mathrm{ml})$ & TNF & 2 -fold & MNCs & 126 \\
\hline TLR3 & Poly(I:C) $(100 \mu \mathrm{g} / \mathrm{ml})$ & $\operatorname{MDP}(1,10 \mu \mathrm{g} / \mathrm{ml})$ & $\begin{array}{l}\text { IL-6 } \\
\text { IL-12 p40 }\end{array}$ & $\begin{array}{l}3 \text {-fold } \\
2 \text {-fold }\end{array}$ & BMDM & 120 \\
\hline TLR5 & Flagellin $(10 \mathrm{ng} / \mathrm{ml})$ & $\operatorname{MDP}(10 \mu \mathrm{g} / \mathrm{ml})$ & TNF & Additive & $\mathrm{MNCs}$ & 126 \\
\hline TLR5 & Flagellin $50(\mu \mathrm{g} / 1)$ & $\operatorname{MDP}(20 \mu \mathrm{g} / \mathrm{l})$ & $\begin{array}{l}\text { TNF } \\
\text { IL-1 } 1 \beta\end{array}$ & $\begin{array}{l}3.4 \text {-fold } \\
3.9 \text {-fold }\end{array}$ & PBMCs & 135 \\
\hline TLR7 & Loxoribin $(5 \mu \mathrm{g} / \mathrm{ml})$ & $\operatorname{MDP}(10 \mu \mathrm{g} / \mathrm{ml})$ & TNF & - & MNCs & 126 \\
\hline TLR7/8 & $\mathrm{R} 848(1 \mathrm{mg} / \mathrm{l})$ & $\operatorname{MDP}(20 \mu \mathrm{g} / \mathrm{l})$ & $\begin{array}{l}\text { TNF } \\
\text { IL-1 } \beta\end{array}$ & $\begin{array}{l}1.7 \text {-fold } \\
2 \text {-fold }\end{array}$ & PBMCs & 135 \\
\hline
\end{tabular}


Table 2. (contimued) Synergy of different stimuli with MDP and other muropeptides

\begin{tabular}{|c|c|c|c|c|c|c|}
\hline Receptor & $\begin{array}{l}\text { Stimulus } \\
\text { (concentration) }\end{array}$ & $\begin{array}{l}\text { Muropeptide } \\
\text { (concentration) }\end{array}$ & End-point & Synergy & Model & Ref. \\
\hline TLR9 & $\mathrm{CpG}(10-1000 \mathrm{nM})$ & $\begin{array}{l}\text { MDP } \\
\text { FK } 156 \\
\text { FK } 565 \\
(1-100 \mu \mathrm{g} / \mathrm{ml})\end{array}$ & IL-8 & $\begin{array}{l}\text { 4-fold } \\
\text { 6-fold } \\
\text { Similar (ns) }\end{array}$ & OCT-diff. THP-1 & 132 \\
\hline TLR9 & $\mathrm{CpG}(2 \mu \mathrm{M})$ & $\begin{array}{l}\text { MDP } \\
\text { MDP (DD) } \\
\text { MurNAc-Ala-Gln } \\
\text { MurNAc-Ala-Gln-Lys } \\
\text { MurNAc-Ala-Gln-DAP } \\
\text { Anhydro-MurNAc-P } \\
\text { Ala-Gln-DA }(50 \mathrm{ng} / \mathrm{ml})\end{array}$ & $\begin{array}{l}\text { TNF } \\
- \\
1200 \text {-fold } \\
1300 \text {-fold } \\
1300 \text {-fold } \\
350 \text {-fold }\end{array}$ & 2000-fold & PBMCs & $\begin{array}{l}\text { Traub } \\
\text { et al., } \\
\text { sub- } \\
\text { mitted }\end{array}$ \\
\hline TLR9 & $\mathrm{CpG}(5 \mu \mathrm{g} / \mathrm{ml})$ & $\operatorname{MDP}(10 \mu \mathrm{g} / \mathrm{ml})$ & TNF & - & MNCs & 126 \\
\hline $\begin{array}{l}\text { T-cell/ } \\
\text { MHCs }\end{array}$ & $\mathrm{SEB}(100 \mathrm{ng} / \mathrm{ml})$ & $\operatorname{MDP}(10 \mathrm{ng} / \mathrm{ml})$ & IL-2 & - & Plasma-free blood & $\begin{array}{c}\text { See } \\
\text { Fig. } 3\end{array}$ \\
\hline CD3 & OKT-3 (5 ng) & $\operatorname{MDP}(50 \mathrm{ng} / \mathrm{ml})$ & IL-2 & - & Plasma-free blood & $\begin{array}{c}\text { See } \\
\text { Fig. } 3\end{array}$ \\
\hline $\mathrm{PKCs}$ & PMA (10 ng/ml) & $\operatorname{MDP}(10 \mathrm{ng} / \mathrm{ml})$ & TNF & 9 -fold & $\begin{array}{l}\text { Human whole } \\
\text { blood }(20 \%)\end{array}$ & $\begin{array}{c}\text { See } \\
\text { Fig. } 3\end{array}$ \\
\hline
\end{tabular}

MNCs, mononuclear cells; PBMCs, peripheral blood mononuclear cells.

findings raised the question, whether muropeptides also act synergistically with other TLR agonists. An overview, focusing on stimulus concentrations, receptor dependence, end-points and cellular models is given in Table 2. TLR2 agonists like LTA from different Grampositive bacteria, MALP-2, PGN and $\mathrm{Pam}_{3} \mathrm{CSK}$ were found to synergize with MDP in human $\mathrm{PBMCs}^{133}$ and various monocytic cell lines. ${ }^{22,75,120,126,132,134,135}$ In contrast, in human whole blood, no synergy of LTA and MDP was found (Fig. 3) and the synergistic effect observed in human PBMCs under serum-free conditions was reduced in the presence of $10 \%$ autologous serum (authors' unpublished results). In line with this, the experiments of Schröder et al. ${ }^{133}$ were performed with human monocytes under low serum conditions (2.5\%). This might indicate that serum components blunt the synergistic effect of LTA and MDP, but this requires further study.

Fewer and, furthermore, controversial results are available for MDP synergism with TLR3, TLR7 and TLR9 agonists. The TLR3 agonist poly(I:C) has been shown to act synergistically with MDP in human primary monocytic cells, ${ }^{120}, 126$ while in the same study, flagellin (TLR5-agonist) as well as loxoribin (TLR7-agonist) and CpG-ODN (TLR-9-agonist) did not. ${ }^{126}$ In contrast, others reported that flagellin as well as the TLR7-agonist R848 (Resiquimod) ${ }^{135}$ and CpGODN (Fig. 3 and Traub et al., submitted) induce syner- gistic cytokine release with MDP and other muropeptides. ${ }^{132}$ Unpublished data from our group obtained with non-TLR agonists show that the membrane-permeable, protein kinase $\mathrm{C}$ activator phorbol myristate acetate (PMA) acts synergistically with MDP, while the superantigen staphylococcal enterotoxin $\mathrm{B}$ (SEB) and antiCD3 antibody OKT-3, do not (Fig. 3).

Taken together, MDP and other muropeptides show synergistic activity with a broad variety of different TLR agonists, indicating a possible interplay of the signal transduction pathways of the different TLR receptors and the cytosolic NOD proteins

\section{Receptors of muropeptides}

For many years, the receptor for MDP and other muropeptides was unknown. Various receptors were discussed as possible candidates, such as the 5-HT receptor, CD14 and the TLR receptors. Only recently, two intracellular proteins of the NOD family, NOD1 and NOD2, were discovered as receptors for MDP and other muropeptides.

\section{5-HT receptor}

MDP has neuropharmacological activities, such as effects on sleep, analgesic properties and influence on behavior. ${ }^{92,136}$ Previous reports from Sevcik and Masek et 


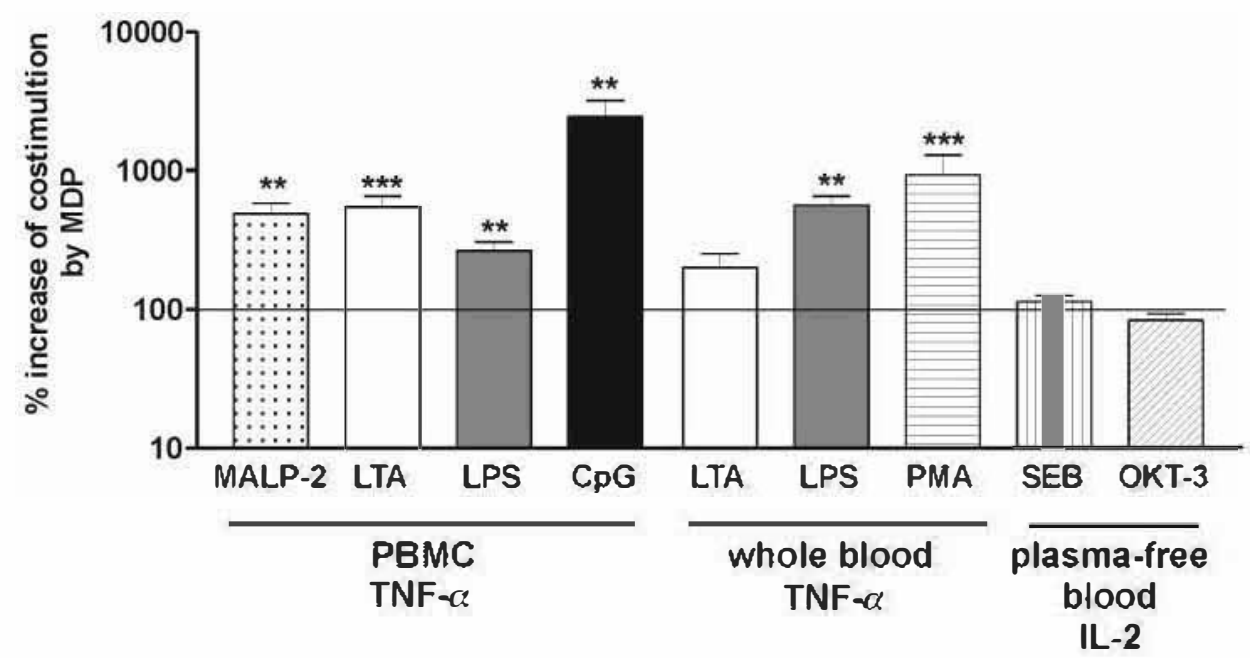

Fig 3. Synergistic effect of MDP with different immune stimuli. PBMCs were stimulated with MALP-2 (10 ng/ml), LTA (Maphylececcus aureus, 10

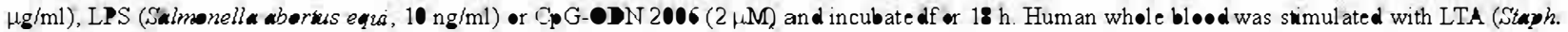
aureus, $100 \mathrm{ng} / \mathrm{ml}$ ), LPS (N. aborus equi, $100 \mathrm{pg} / \mathrm{ml}$ ) or horbol myristate acetate (PMA, $10 \mathrm{ng} / \mathrm{ml}$ ) and incubatedf or $24 \mathrm{~h}$. Masma-free bl $\bullet \bullet d$ was

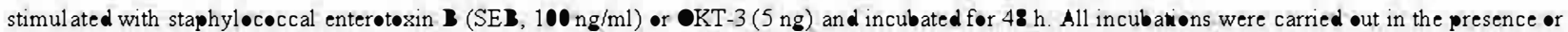

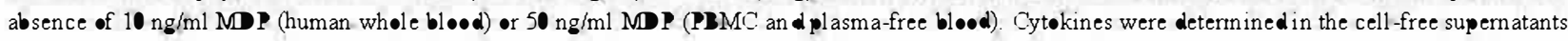

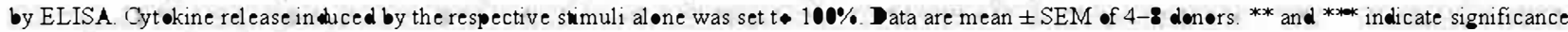
versus the respective stimulus al one

$\boldsymbol{a l}^{137,138}$ suggested that these activities might be mediated by interactions with the serotoninergic system via the 5HT receptor. However, recent reports from the same group showed that this is not the case when physiologically relevant concentrations in the nanomolar range are employed and no interaction of MDP with either the 5$\mathrm{HT}_{4}$ or the $5-\mathrm{HT}_{1 \mathrm{~A}}$ receptor was observed. ${ }^{139,140}$

\section{CD14}

Membrane CD14 (mCD14) is a glycosylphosphatidylinositol-anchored cell-surface molecule found on cells of the myeloid lineage. Since it lacks a cytoplasmic domain, it cannot ransmit signals into the cell. The anchor is missing in soluble CD14 (sCD14), which is present in hurnan serum as an acute phase protein. CD14 is thought to be an adaptor molecule accepting complexes made up of LBP and pathogen-derived ligands and passing the pathogen-derived ligand on to a TLR, which bears a transmembrane domain, resulting in intracellular signaling.

The role of CD14 in MDP-dependent cell activation is controversial. Several findings argue in favor of CD14 as an MDP receptor. Anorectic effects of MDP were abrogated in CD14-knockout mice. ${ }^{10}$ In hurnan monocytes, the cytokine release induced by the disaccharide-pentapeptide (GlcNAc-MurNAc-Ala-isoGln-mes $\bullet-D A P-A l a-A l a)$ was enhanced by pre-incubation with $\mathrm{SCD} 14$, while antiCD14 mAb blocked these effects. ${ }^{141}$ MDP was also shown to bind to $\mathrm{mCD} 14$, preventing the binding of soluble PGN. ${ }^{142}$ In human gingival epithelial cells, CD14 and LBP, but not LBP alone, enhanced MDP-stimulated activation $^{143}$ arguing for a role of CD14 as a possible MDP receptor. In line with human gingival fibroblasts expressing high CD14 levels, MDP-induced IL-8 release was inhibited by anti-CD14 mAb, while in human periodontal ligament fibroblasts, expressing low CD14, this was not the case. These results indicate that other CD14independent pathways must exist as well. ${ }^{144}$ In line with this, MDP did not induce reporter gene expression in constitutively CD14 expressing $\mathrm{CH}$ cells ${ }^{145}$ and in monocytic cell lines, cytokine induction by LPS/MDP 75 or MDP alone ${ }^{22}$ could not be inhibited by anti-CD14 $\mathrm{mAb}$. Others have shown that monomeric MDP does not bind to sCD14, while MDP or GlcNAc-MDP immobilized on agarose does. ${ }^{146}$ These investigators concluded that solid-bound MDP is needed for CD14 binding.

So far, these results point to a possible interaction of MDP with CD14. Since results of ransfection experiments are strongly affected by ransfection efficacy and proper protein surface expression and the use of blocking antibodies is limited by the antibody blocking capacity, all of which are not always sufficiently controlled, further experiments with cells from CD14 knockout mice could shed some more light on this subject. Again, the lack of exclusion of LPS contaminations as well as the use of different MDP concentrations, ranging from 1 $\mu \mathrm{g} / \mathrm{ml}$ to $100 \mu \mathrm{g} / \mathrm{ml}$ might be a reason for some of the controversy.

\section{TLRS}

Each TLR recognizes one or more specific PAMPs. Ligand recognition initiates a signaling cascade, activat- 
ing the immune response. The role of TLR2 and TLR4 in MDP signaling has been addressed in several studies. In human gingival epithelial cells, MDP-induced IL-8 release could be reduced by pre-treatment with an antiTLR2 $\mathrm{mAb}^{143}$ and reduced food intake caused by MDP was not restored in TLR4-deficient mice, but in TLR2 knockout mice. ${ }^{100}$ However, neither TLR4 nor TLR2 dependence was observed when $\mathrm{CH} \bullet$ cells were ransfected with CD14/TLR2, CD14/TLR4 or CD14/TLR4/TLR2 and stimulated with MDP. ${ }^{145,147}$ In line with this, no inhibitory effect of anti-TLR2 or antiTLR $4 \mathrm{mAb}$ on cytokine release was found in monocytic cell lines, ${ }^{22,75}$ human periodontal ligament or gingival fibroblasts as well as in IFN- $\gamma$-primed oral epithelial cells. ${ }^{23,144}$ Additionally, MDP-stimulated cytokine release in monocytic OCT-differentiated U937 cells, which do not express TLR2, indicates TLR2-independent activity. ${ }^{22}$ Some stimuli such as $\mathrm{Pam}_{3} \mathrm{CSK}$ and MALP-2 require dimerization of TLR2 with TLR1 or TLR6 for signal ransduction. ${ }^{148,149}$ Since neither expression of TLR2 with TLR1 nor TLR6 enabled MDP to induce NF-1 $\mathrm{kB}$ activation, heterodimerization did not appear to be the missing link. ${ }^{16} \mathrm{MDP}$ stimulation enhanced the basal transcription of MyD88 mRNA in THP-1 cells, an important adaptor molecule for TLRs, which might provide a possible mechanism for synergistic actions with TLR agonists. ${ }^{22}$ Although LPS induced up-regulation of MyD88 mRNA as well, no clear synergistic up-regulation of MyD88 mRNA could be observed with LPS plus MDP. ${ }^{22}$

Taken together, most results argue against a role of TLR2 or TLR4 as the MDP receptor in the initiation of immune responses, although TLR2 seems to play a role in the anorectic effects; not all TLRs have been investigated so far.

\section{NOD proteins}

Recently, another family of PRRs, the cytoplasmic nucleotide-binding oligomerization domain (NOD) family of proteins, which seems to play an important role in in racellular immune defense, has been identified. The NOD proteins share homology with a class of plant proteins ( $\mathrm{R}$ proteins) that recognize invading pathogens and mediate a defense response, resulting in plant-disease resistance. ${ }^{151}$ The NOD family of proteins has several members, two of them, NOD1 and NOD2, were initially shown to recognize LPS, ${ }^{152}$ but recent studies evidenced that NOD1 and NOD2 actually do not detect LPS, but PGN fragments. It was shown that such fragments, which had co-extracted with LPS during purification in the original study, had led to the false assumption in the first report. ${ }^{44,153}$

\section{NOD1}

NOD1 consists of three domains: (i) a centrally located nucleotide oligomerization domain (NOD); (ii) C-terminal leucine-rich repeats (LRR) for bacterial recognition; and (iii) the N-terminal effector domain, which contains one caspase recruiment domain (CARD). NOD1 is expressed in multiple tissues. ${ }^{154,155}$ Carneiro et al. ${ }^{156}$ hypothesized that, when no stimuli are present, NOD proteins are negatively regulated by their LRR by folding. NOD1 detects only PGN fragments containing DAP at the third position, thereby distinguishing between PGN-derived compounds from Gram-negative and Gram-positive bacteria. ${ }^{153}$ The precise structure of the PGN-derived compound was identified as a DAP-containing naturally occurring muropeptide, the GlcNAcMurNAc-tripeptide. ${ }^{153}$ Furthermore, NOD1 detects the DAP-containing muropeptides MurNAc-tripeptide, which has only one sugar moiety, as well as a UDPMurNAc-tripeptide, which is a precursor of the PGN biosynthesis pathway. MurNAc-L-Ala-D-Glu or MurNAc-tetrapeptide are not detected, pointing to the importance of the terminal meso-DAP. ${ }^{157}$ The dipeptide $\gamma$-D-glutamyl-meso-DAP has been identified as the minimal active motif, 157 indicating that NOD1 sensing relies only on the peptidic moiety. However, the ripeptide LAla- $\gamma$-D-Glu-meso-DAP showed higher activity, suggesting that the L-Ala residue is required for optimal detection by NOD1 ${ }^{157} \mathrm{NOD} 1$ also detects a lactoyl-ripeptide containing DAP, though only weakly in comparison to the GlcNAcMurNAc-ripeptide, MurNAc-tripeptide or the tripeptide alone ${ }^{157}$ Another synthetic dipeptide (i.e. $\gamma$-D-glutamicmeso-DAP) can also stimulate NOD1. ${ }^{44}$

\section{NOD2}

The major structural difference between NOD1 and $\mathrm{NOD} 2$ is the presence of two amino-terminal CARD domains in NOD2. NOD2 is mainly expressed in monocytes, macrophages, dendritic cells, granulocytes and to a lesser extent in T-lymphocytes. Recent publications have shown by immunostaining of intestinal tissues that NOD2 is highly expressed in Paneth cells in the terminal ileum. ${ }^{159-161}$ Furthermore, NOD2 mRNA was found in unstimulated epithelial cells from normal colon at low levels, but expression was increased in macrophages and intestinal epithelial cells from patients with Crohn's inflammatory bowel disease. ${ }^{15,162}$ LPS and TNF induce up-regulation of NOD2 mRNA in myeloblastic and epithelial cells. The authors suggested that the activation of NF- $\kappa \mathrm{B}$ by pro-inflammatory stimuli by enteropathogens or pathogenic bacteria could induce expression of NOD2 and lead to a positive feedback loop, resulting in secretion of pro-inflammatory cytokines and chemokines from epithelial cells..$^{158,163}$

A large number of studies also point to a role of NOD2 as a susceptible gene involved in Crohn's disease. ${ }^{135,164-166}$ The most common associated mutation is a frame-shift mutation resulting in a NOD2 protein with a truncated terminal LRR that cannot detect MDP. ${ }^{164}$ 
NOD2 mutations may disable normal local responses in the intestinal mucosa, hindering control of bacterial infection and eventually leading to systemic responses and aberrant inflammation. ${ }^{167}$

Since MDP is a common PGN motif, NOD2 is a broad sensor for Gram-negative and Gram-positive bacteria. Girardin et $a l^{157}$ have extensively studied the structural requirements of muropeptides to serve as NOD2 agonists. They found that GlcNAc-MurNAc-L-Ala-DisoGln, MurNAc-L-Ala-D-Glu, as well as muramyl tripeptides with lysine or omithine and to a lesser extent structures with amidated DAP at the third position, are recognized by NOD2. PGN precursors like UDPMurNAc-ripeptides are also recognized by NOD2. As minimal structure, an intact MurNAc group substituted with a peptide chain is necessary for NOD2 signaling, because peptides lacking the MurNAc sugar moiety do not activate NOD2. ${ }^{157}$ Synthetic MDP-analogues, in which the conformation of the L-Ala had been changed to D-Ala or D-isoGIn to L-isoGln revealed that the recognition process is stereoselective. ${ }^{15} \mathrm{~A}$ positive interaction of the signaling pathways of NOD1 and NOD2 with different TLRs is probably the basis for the observed synergism of muropeptides with TLR agonists, ${ }^{120,126,132}$ but the precise molecular basis of the interaction is not known to date. A recent report has shown that NOD2 can inhibit TLR2-mediated NF- $\mathrm{KB}$ activation, ${ }^{168}$ while others reported a modulation of the TLR2 pathways by NOD2. ${ }^{169}$ Furthermore, NOD proteins might be important for cells in which TLR are absent or down-regulated.

\section{Internalization of muropeptides}

Although there is evidence that NOD proteins play a role in recognition of $P G N$ breakdown products, it is not clear how the muropeptides come into contact with the cytosolic NOD proteins. In most experiments, the investigators used ransfection reagents or digitonin-permeabilized cells, which allow the muropeptides to enter the cytosol directly ${ }^{153}$ In the case of immune cells, phagocytosis of bacteria is probably the physiological process. After phagocytosis, the bacteria become degraded by lysosomal proteases and muropeptides may become available to intracellular proteins. How muropeptides reach the cytosol from the phagosome remains unclear. ${ }^{156}$

In non-phagocytic cells, direct bacterial invasion into the cell or by a bacterial transfer apparatus is imaginable. Entero-invasive bacteria like Salmonella, invasive E. coli, Listeria, Shigella or Yersinia, for example, induce their own uptake by epithelial cells of the intestinal mucosa. ${ }^{170}$ Girardin et al. ${ }^{171}$ demonstrated, that NF-1CB activation by Shigella flexneri was inhibited by overexpression of dominant-negative NOD1. Furthermore, NFKB activation induced by Streptococcus pneumoniae, was dependent on NOD2, as well as NOD1, and NOD2 mRNA expression was up-regulated after pneumococcal infection. ${ }^{172}$ Two studies indicate a direct anti-bacterial activity of NODs. The number of viable, internalized Salmonella typhimurium in Caco-2 cells, that were stably transfected with NOD2, was lower than in vectortransfected cells. ${ }^{173}$ In line with this, infection with entero-invasive $E$. coli was avoided in dominant-negative NOD1 colon epithelial cells. ${ }^{174}$

Exracellular, non-invasive bacteria, such as cagPAIpositive Helicobacter pylori, are recognized by NOD1; also, NOD1-deficient and NOD1-knockout mice were more susceptible to infection with cagPAI-positive $H$. pylori strains. ${ }^{175}$ CagPAI genes are proposed to encode a type IV secretion apparatus, and the secretion of PGN fragments by the type IV secretion system, was necessary for NOD1-dependent activation of NF- $\mathrm{KB}$. Digestion and identification of the high-performance liquid chromatography fraction of the PGN of H. pylori showed the GlcNAcMurNAc-ripeptide as the active component. ${ }^{175}$ Another hypothesis is the ransport of MDP by the intestinal epithelial apical di-/ripeptide ransporter hPepT 1 , which in turm has been shown to activate the cell via NOD2. ${ }^{-8}$

Although a direct interaction of muropeptides with NOD proteins has not been shown yet and the route of entering the cell cytoplasm is not fully clarified, there is strong evidence that the NOD proteins are muropeptide receptors or at least possible downstream molecules in muropeptide signaling.

\section{CONCLUSIONS}

Free muropeptides are present in the body during infection. They are naturally released during bacterial growth and division, by antibiotic treatment or the activity of lytic host enzymes. The diversity of PGNs from different bacterial strains leads to a variety of possible muropeptide structures. Muramyl dipeptide (MDP) is a prominent motif and represents the minimal biologically active structure. Surprisingly, larger structures do not exert enhanced biological activity. The cytosolic proteins NOD1 and NOD2 have been identified as important muropeptide receptors, although possible contributions of CD14 and TLR cannot be fully excluded. Remarkably, these NOD proteins are intracellular receptors suggesting a role for phagocytosed or in racellular pathogens. Muropeptides have diverse effects on the immune system: somnogenic effects, reduction of food intake and, most important, they are potent immune amplifiers. Direct effects on immune cells appear to be rare, i.e. they are often only observed at very high concentrations or when proper exclusion ofLPScontamination is missing, but they show potent priming and synergistic effects with other immune stimuli. Taken 
together, this illustrates that, during bacterial infection, it is most probably a combined sensing of immune stimuli by different immune receptors that orchestrates the immune response.

\section{ACKNOWLEDGEMENTS}

ST was supported by the Landesgraduiertenforderung (LGF) and $\mathrm{CH}$ is supported by a $\mathrm{M}$ v. Wrangell Habilitationsstipendium.

\section{REFERENCES}

1. Seydel U, Schromm AB, Blunck R, Brandenburg K. Chemical structure, molecular confornation, and bioactivity of endotoxins. Chem Immund 2000; 74: 5-24.

2. Aasjord P, Grov A. Immunoperoxidase and electron microscopy studies of staphylococcal lipoteichoic acid. Acta Pathol Microbiol Scand [B] 1980; 88: 47-52.

3. Morath S, Stadelmaier A, Geyer A, Schmidt RR, Hartung T. Synthet ic lipoteichoic acid from Staphylececcus aureus is a potent stimulus of cytokine release. JE.xp Med 2002; 195 : $1635-1640$.

4. Morath S, Geyer A, Spreitzer I, Hermann C, Hartung T. Structural decomposition and heterogeneity of commercial lipoteichoic acid preparations. Infect Immun 2002; 70::938-944.

5. Dmitriev BA, Toukach FV, Holst O, Rietschel ET, Ehlers S. Tertiary structure of Staphylecoccus aureus cell wall murein. $J$ Bacteriol 2004; 186: :7141-7148.

6. Vollmer W, Holtje $\Omega$. The architecture of the murein (peptidoglycan) in Gram-negative bacteria: vertical scaffold or horizontal layer(s)? J Bacteriol 2004; 186: 5978-5987.

7. Ellouz F, Adam A, Ciorbaru R, Lederer E. Minimal structural requirements for adjuvant activity of bacterial peptidoglycan derivatives. Biochem Biøphys Res Commun 1974; 59: 1317-1325.

8. Beutler B. Inferences, questions and possibilities in Toll-like receptor signalling. Nature 2004; 430: 257-263.

9. Zhang D, Zhang G, Hayden MS et al. A Toll-like receptor that prevents infection by uropathogenic bacteria. Science 2004; 303: 1522-1526.

10. Tabeta $K$, Georgel P. Janssen E et al. Toll-like receptors 9 and 3 as essential components of innate immune defense against mouse cytomegalovirus infection. Proc Nal Acad Sci USA 2004; 101: 3516-3521.

11. Yarovinsky F, Zhang D, Andersen JF el al. TLR11 activation of dendritic cells by a protozoan profilin-like protein. Science 2005; 308: 1626-1629.

12. Medzhitov $R$ Toll-like receptors and innate immunity. Nat Rev Immunol 2001; 1: :135-145.

13. Dunne A, Ejdeback M, Ludidi PL, O'Neill LA, Gay NJ. Structural complementarity of Toll/interleukin-1 receptor domains in Toll-like receptors and the adaptors Mal and MyD88. $J$ Biol Chem 2003; 278: 41443-41451.

14. Akira S, Takeda K. Toll-like receptor signalling. Nat Rev Immunol 2004; 4: 499-511.

15. Poltorak A, HeX, Smirnova I et al . Defective LPS signaling in $\mathrm{C} 3 \mathrm{H} / \mathrm{HeJ}$ and $\mathrm{C} 57 \mathrm{BL} / 10 \mathrm{ScCr}$ mice: mutations in Tlr4 gene. Science 1998; 282: 2085-2088.

16. Hoshino $\mathrm{K}$, Takeuchi $\mathrm{O}$, Kawai $\mathrm{T}$ et al. Toll-like receptor 4 (TLR4)-deficient mice are hyporesponsive to lipopolysaccharide: evidence for TLR4 as the Lps gene product. $J$ Immunol 1999; 162: 3749-3752

17. Wright SD, Ramos RA, Tobias PS, Ulevitch RJ, Mathison JC CD14, a receptor for complexes of lipopolysaccharide (LPS) and LPS binding protein. Science 1990; 249: 1431-1433.

18. Beutler B, Rietschel ET. Innate immune sensing and its roots: the story of endotoxin. Nat Rev Immunol 2003; 3: 169-176.

19. Shimazu R, Akasti S, Ogata Hetal.MD-2, a molecule that confers lipopolysaccharide responsiveness on Toll-like receptor 4. JE xp Med 1999; 189: 1777-1782.

20. Schromm AB, Brandenburg K, Loppnow Her al Biological activities of lipopolysaccharides are deternined by the shape of their lipid A portion. EurJ Biochem 2000; 267: 2008-2013.

21. Takeuchi O, HoshinoK, Kawai T elal. Differential roles of TI.R2 and TI.R4 in recognition of Gram-negative and Grampositive bacterial cell wall components. Immunity 1999 ; 11 : $443-451$.

22. Yang S, Tamai R, Akashi S et al. Synergistic effect of muramyldipeptide with lipopolysacchar ide or lipoteichoic acid to induce inflammatory cytokines in human monocytic cells in culture. Infect Immun 2001; 69: 2045-2053.

23. Uehara A, Sugawara S, Takada H. Priming of human oral epithelial cells by interferon-gamma to secrete cytokines in response to lipopolysaccharides, lipoteichoic acids and peptidoglycans. J Med Micr biel 2002; 51: 626-634.

24. Lehner MD, Morath S, Michelsen KS, Schumann RR, Hartung T. Induction of cross-tolerance by lipopolysaccharide and highly purified lipoteichoic acid via different Toll-like receptors independent of paracrine mediators. J Immunol 2001; 166 5161-5167.

25. Opitz B, Schroder NW, Spreitzer I et al. Toll-like receptor-2 mediates Treponema glycolipid and lipoteichoic acid-induced NF-kappaB translocation. J Biol Chem 2001; 276: :22041-22047.

26. Travassos LH, Girardin SE, Philpott DJ et al. Toll-like receptor 2-dependent bacterial sensing does not occur via peptidoglycan recognition. EMBO Report 2004; 5: 1000-1006.

27. Deininger S, Stadelmaier A, Von Aulock S, Morath S, Schmidt $R R$, Hartung T. Definition of structural prerequisites for lipoteichoic acid-inducible cytokine induction by synthetic derivatives. $J$ Immunel 2003; 170: 4134-4138.

28. Sugiyama A, Arakaki R, Ohnishi T, Arakaki N, Daikuhara Y, Takada H. Lipoteichoic acid and interleukin 1 stimulate synergistically production of hepatocyte growth factor (scatter factor) in human gingival fibroblasts in culture. Infect Immun 1996; 64: :1426-1431.

29. Gao JJ, Xue Q, Zuvanich EG, Haghi KR, Morrison DC. Commercial preparations of lipoteichoic acid contain endotoxin that contributes to activation of mouse macrophages in vitro. Infect Immun 2001; 69: 751-757.

30. Heanmi $\mathrm{H}$, Takeuchi $\mathrm{O}$, Kawai Te al. A Toll-like receptor recognizes bacterial DNA. Nature 2000; 408: 740-745.

31. Ahmad-Ne jad P, Hacker H, Rutz M, Bauer S, Vabulas RM, Wagner H. Bacterial OPG-DNA and lipopolysaccharides activate Toll-like receptors at distinct cellular compartments. EurJ Immunel 2002; 32: 1958-1968.

32. Latz E, Schoenemeyer A, Visintin A ef al. TLR9 signals after translocating from the ER to CpG DNA in the lysosome. Nat Immunel 2004; 5: 190-198.

33. Wang JE, Jorgensen PF, Almlof Metal. Peptidoglycan and lipoteichoic acid from Staphylececcus aureus induce tumor necrosis factor alpha, interleukin 6 (IL-6), and IL-1 1 production in both $\mathrm{T}$ cells and monocytes in a human whole blood model Infect Immun 2000; 68: 3965-3970.

34. Thiemermann C. Interactions between lipoteichoic acid and peptidoglycan from Staphylececcus aureus: a structural and 
functional analysis. Microbes Infect 2002; 4: 927-935

35. Dziarski R. Recognition of bacterial peptidoglycan by the innate immune system. Cell Mol Life Sci 2003; 60: 1793-1804.

36. Xu Z, Dziarski R, Wang Q, Swartz K, Sakamoto KM, Gupta D. Bacterial peptidoglycan-induce TNF-alpha transcription is mediated through the transcription factors Egr-1, Elk-1, and NFkappaB. J Immunol 2001; 167: :6975-6982.

37. Yoshimura A, Lien E, Ingalls RR, Tuomanen E, Dziarski R, Golenbock D. Recognition of Gram-positive bacterial cell wall components by the innate immune system occurs via Toll-like receptor 2. J Immunel 1999; 163: 1-5.

38. Schwandner R, Dziarski R, Wesche H, Rothe M, Kirschning CJ Peptidoglycan- and lipoteichoic acid-induced cell activation is mediated by Toll-like receptor 2. JBi॰l Chem 1999; 274 : 17406-17409.

39. Mitsuzawa H, Wada I, Sano Het al. Extracellular Toll-like receptor 2 region containing Ser40-Ile64 but not Cys30-Ser39 is critical for the recognition of Staphylececcus aureus peptidoglycan. J Biel Chem 2001; 276: 41350-41356.

40. Kyburz D, Rethage J, Seibl R et al. Bacterial peptidoglycans but not $\mathrm{CpG}$ oligodeoxynucleotides activate synovial fibroblasts by Toll-like receptor signaling. Arthritis Rheum 2003; 48: 642-650

41. Dziarski R, Gupta D. Staphylececcus aureus peptidoglycan is a Toll-like receptor 2 activator: a re-evaluation. Infect Immun 2005; 73: $5212-5216$

42. Hoebe K, Georgel P, Rutschmann Set al. CD36 is a sensor of diacylglycerides. Nat ure 2005; 433: 523-527.

43. Chamaillard M, Girardin SE, Viala J, Philpott DJ. Nods, Nalps and Naip: intracellular regulators of bacterial-induced inflammation. Cell Microbiøl 2003; 5: 581-592.

44. Chamaillar M, Hashimoto M, Horie Y et al. An essential role for NOD1 in host recognition of bacterial peptidoglycan containing diaminopimelic acid. Nat Immunel 2003; 4: 702-707.

45. Girardin SE, Boneca IG, Viala J et al. Nod2 is a general sensor of peptidoglycan through muramyl dipeptide (MDP) detection. $J$ Biøl Chem 2003; 278: 8869-8872.

46. Schleif er KH, Kandler O. Peptidoglycan types of bacterial cell walls and their taxonomic implications. Bacteriel Rev 1972; 36 : 407-477.

47. Holt je JV. Growth of the stress-bearing and shape-maintaining murein sacculus of Escherichia celi. Microbiel Mel Biel Rev 1998; 62: 181-203.

48. Navarre WW, Schneewind O. Surface proteins of Gram-positive bacteria and mechanisms of their targeting to the cell wall envelope. Micrøbiøl Mel Bi॰l Rev 1999; 63: 174-229.

49. Severin A, Tomasz A. Naturally occurring peptidoglycan variants of Streptececcus pneumeniae. J Bacteriel 1996; 178: 168-174.

50. Shockman GD, Hölt je J-V. Microbial Peptideglycan (Murein) Hydrolases. Amsterdam: Elsevier, 1994.

51. Harz H, Burgdorf K, Hölt je J-V. Isolation and separation of the glycan strands from murein of Escherichia cali by reversedphase high-performance liquid chromatography. Anal Biechem 1990; 190: $120-128$

52. Vermeulen MW, Gray GR. Processing of Bacillus subtilis peptidoglycan by a mouse macrophage cell line. Infect Immun 1984; 46: $476-483$

53. Kerr DE, Plaut $\mathrm{K}$, Bramley A Jet al. Lysostaphin expression in mammary glands confers protection against staphylococcal infection in transgenic mice. Nat Biotechnol 2001; 19: 66-70.

54. Horsburgh GJ, Atrih A, Williamson MP, Foster SJ. LytG of Bacillus subtilis is a novel peptidoglycan hydrolase: the major active glucosaminidase. Biechemistry 2003; 42::257-264.

55. Boneca IG. The role of peptidoglycan in pathogenesis. Curr Opin Microbi॰l2005; 8: 46-53.

56. Wang ZM, Li X, Cocklin RR et al. Human peptidoglycan recognition protein-L is an $N$-acetylmuramoyl-L-alanine amidase. $J$
Biel Chem 2003; 278: 49044-49052

57. McLaughlan AM, Foster SJ. Molecular characterization of an autolytic amidase of Listeria møn॰cytøgenes EGD. Micrøbiøløgy 1998; 144: 1359-1367.

58. Pappenheimer JR, Koski G, Fencl V, Kamovsky ML, Krueger J Extraction of sleep-promoting factor $\mathrm{S}$ from cerebrospinal fluid and from brains of sleep-deprived animals. $J$ Neurephysiel 1975 ; 38: $1299-1311$

59. Krueger JM, Pappenheimer JR, Kamovsky ML. The composition of sleep-promoting factor isolated from human urine. $J \mathrm{Bi} \bullet \mathrm{l}$ Chem 1982; 257: 1664-1669

60. Martin SA, Kamovsky ML, Krueger JM, Pappenheimer JR, Biemann K. Peptidoglycans as promoters of slow-wave sleep. I. Structure of the sleep-promoting factor isolated from human urine. J Biøl Chem 1984; 259: 12652-12658.

61. Krueger JM, Karnovsky ML, Martin SA, Pappenheimer JR, Walter J, Biemann K. Peptidoglycans as promoters of slow-wave sleep. II. Somnogenic and pyrogenic activities of some naturally occurring muramyl peptides; correlations with mass spectrometric structure determination. J Biøl Chem 1984; 259 $12659-12662$

62. Fox A, Schwab JH, Cochran T. Muramic acid detection in mammalian tissues by gas-liquid chromatography-mass spectrometry. Infect Immun 1980; 29: 526-531.

63. Kozar MP, Krahmer MT, Fox A, Gray BM. Failure To detect muramic acid in normal rat tissues but detection in cerebrospinal fluids from patients with pneumococcal meningitis. Infect Immun 2000; 68:4688-4698.

64. Sen Z, Kamovsky ML. Qualitative detection of muramic acid in normal mammalian tissues. Infect Immun 1984; 43: 937-941.

65. Christensson B, Gilbart J, Fox A, Morgan SL. Mass spectrometric quantitation of muramic acid, a bacterial cell wall component, in septic synovial fluids. Arthritis Rheum 1989; 32 1268-1272.

66. Lehtonen L, Kortekangas P, Oksman P, Eerola E, Aro H, Toivanen A. Synovial fluid muramic acid in acute inflammatory arthritis. Br J Rheumat $1994 ; 33$ : 1127-1130.

67. Bal K, Larsson L. New and simple procedure for the determination of muramic acid in chemically complex environments by gas chromatography-ion trap tandem mass spectrometry. $J$ Chromategr B Biemed Sci Appl 2000; 738: 57-65.

68. Vavricka SR, Musch MW, Chang JE et al. hPepT1 transports muramyl dipeptide, activating NF-kappaB and stimulating IL-8 secretion in human colonic Caco2/bbe cells. Gastrenteroløgy 2004; 127: :1401-1409

69. Tomasic J, Ladesic B, Valinger Z, Hrsak I. The metabolic fate of ${ }^{14} \mathrm{C}$-labeled peptidoglycan monomer in mice. I. Identification of the monomer and the corresponding pentapeptide in urine. Biechim Biephys Acta 1980; 629: :77-82.

70. Yapo A, Petit JF, Lederer E, Parant M, Parant F, Chedid L. Fate of two ${ }^{14} \mathrm{C}$-labelled muramyl peptides: Ac-Mur-L-Ala-gamma-DGlu-meso-A2pm and Ac-Mur-L-Ala-gamma-D-Glu-meso-A2pmD-Ala-D-Ala in mice. Evaluation of their ability to increase non specific resistance to Klebsiella infection. Int J Imminophamacel 1982; 4: 143-149.

71. Fosset S, Fromentin G, Rampin O, Lang V, Mathieu F, Tome D. Pharmacokinetics and feeding responses to muramyl dipeptide in rats. Physiel Behav 2003; 79: 173-182.

72. Fox A, Fox K. Rapid elimination of a synthetic adjuvant peptide from the circulation after systemic administration and absence of detectable natural muramyl peptides in normal serum at current analytical limits. Infect Immun 1991; 59: 1202-1205.

73. Dzierzbicka K, Kolodziejczyk AM. Muramyl peptides - synthesis and biological activity. Polish J Chem 2003; 77: 373-395.

74. Dzierzbicka K, Kolodziejczyk AM. Synthesis and antitumıor activity of conjugates of muramyldipeptide or normuramyldipeptide with 
hydroxyacridine/acridone derivatives. $J$ Med Chem 2003; 46: 183-189.

75. Wolfert MA, Murray TF, Boons GJ, Moore JN. The origin of the synergistic effect of muramyldipeptide with endotoxin and peptidoglycan. J Biel Chem 2002; 277: 39179-39186.

76. Dinarello CA, Krueger JM. Induction of interleukin 1 by synthetic and naturally occurring muramyl peptides. Fed Proc 1986; 45: 2545-2548.

77. Safavi KE, Nichols FC. Effects of a bacterial cell wall fragment on monocyte inflammatory function. $J$ End $\bullet 2000$; 26: 153-155.

78. Martinon F, Burns K, Tschopp J. The inflammasome: a molecular platform triggering activation of inflammatory caspases and processing of proIL-beta. Mel Cell 2002; 10: 417-426.

79. Martinon F, Agostini L, Meylan E, Tschopp J. Identification of bacterial muramyl dipeptide as activator of the NALP3/cryopyrin inflammasome. Curr Biel 2004; 14: 1929-1934

80. Wang JE, Jorgensen PF, Ellingsen EA et al. Peptidoglycan primes for LPS-induced release of proinflammatory cytokines in whole human blood. Sheck 2001; 16: 178-182.

81. Traub S, Kubasch N, Morath S et al. Structural requirements of synthetic muropeptides to synergize with lipopolysaccharide in cytokine induction. J Biel Chem 2004; 279: 8694-8700

82. Nagao S, Akagawa KS, Yamada K, Yagawa K, Tokunaga T, Kotani S. Lack of response of murine peritoneal macrophages to in vitre activation by muramyl dipeptide (MDP). I. Macrophage activation by MDP is species dependent. Micrøbiel Immun 1990; 34: 323-335

83. Le Contel C, Temime N, Charron DJ, Parant MA. Modulation of lipopolysaccharide-induced cytokine gene expression in mouse bone marrow-derived macrophages by muramyl dipeptide. $J$ Immunel 1993; 150: 4541.

84. Srividya S, Roy RP, Basu SK, Mukhopadhyay A. Scavenger receptor-mediated delivery of muramyl dipeptide activates antitumor efficacy of macrophages by enhanced secretion of tumor-suppressive cytokines. $J$ Leukec Biøl 2000; 67: 683-690.

85. Parant M, Parant F, Vinit MA, Jupin C, Noso Y, Chedid L. Priming effect of muramyl peptides for induction by lipopolysaccharide of tumor necrosis factor production in mice. $J$ Leukec Bi॰l 1990; 47: 164-169

86. Baschang G. Muramylpeptides and lipopeptides: studies towards immunostimulants. Tetrahedron 1989; 45: :6331-6360.

87. Mukherjee K, Parashuraman S, Krishnamurthy G et al. Diverting intracellular trafficking of Salmonella to the lysosome through activation of the late endocytic Rab7 by intracellular delivery of muramyl dipeptide. J Cell Sci 2002; 115: 3693-3701.

88. Chedid L, Parant M, Parant F, Lefrancher P, Choay J, Lederer E. Enhancement of nonspecif ic immunity to Klebsiella pneumeniae infection by a synthetic immunoad juvant (N-acetylmuramyl-Lalanyl-D-isoglutamine) and several analogs. Proc Natl Acad Sci USA 1977; 74: 2089-2093.

89. Fraser-Smith EB, Matthews TR. Protective effect of muramyl dipeptide analogs against infections of Pseudomenas aeruginesa or Candida albicans in mice. Infect Immun 1981; 34: 676-683.

90. Sarkar K, Das PK. Protective effect of neoglycoprotein-con jugated muramyl dipeptide against Leishmania donovani infection: the role of cytokines. $J$ Immunel 1997; 158: 5357-5365.

91. Johannsen L, Obal Jr F, Kapas L, Kovalzon V, Krueger JM Somnogenic activity of muramyl peptide-derived immune adjuvants. Int $J$ Immuno pharmacel 1994; 16: 109-116.

92. Krueger JM, Majde JA. Microbial products and cytokines in sleep and fever regulation. Crit Rev Immunel 1994; 14: 355-379.

93. Obal Jr F, Krueger JM. Biochemical regulation of non-rapid-eyemovement sleep. Frent Biesci 2003; 8: :d520-550

94. Chen L, Taishi P, Majde JA, Peterfi Z, Obal Jr F, Krueger JM The role of nitric oxide synthases in the sleep responses to tumor necrosis factor-alpha. Brain Behav Immun 2004; 18: 390-398.
95. Nelson EA, Wong Y, Yu LM, Fok TF, Li K. Effects of hyperthermia and muramyl dipeptide on IL-1beta, IL-6, and mortality in a neonatal rat model. Pediatr Res 2002; 52: 886-891.

96. Plata-Salaman CR. 1998 Curt P. Richter Award. Brain mechanisms in cytokine-induced anorexia. Psychoneureendecrinelegy 1999; 24: 25-41.

97. Langhans W. Bacterial products and the control of ingestive behavior: clinical implications. Nutrition 1996; 12: 303-315.

98. Gayle D, Ilyin SE, Flynn MC, Plata-Salaman CR. Lipopolysaccharide (LPS)- and muramyl dipeptide (MDP)induced anorexia during refeeding following acute fasting: characterization of brain cytokine and neuropeptide systems mRNAs. Brain Res 1998; 795: 77-86

99. Porter MH, Hrupka BJ, Altreuther G, Arnold M, Langhans W. Inhibition of TNF-alpha production contributes to the attenuation of LPS-induced hypophagia by pentoxifylline. Am J Physid 2000; 279: R2113-2120.

100. von Meyenburg C, Hrupka BH, Arseni jevic D, Schwartz GJ, Landmann R, Langhans W. Role for CD14, TLR2, and TLR4 in bacterial product-induced anorexia. Am J Physi $12004 ; 287$ R298-305.

101. Burroughs M, Rozdzinski E, Geelen S, Tuomanen E. A structureactivity relationship for induction of meningeal inflammation by muramyl peptides. J Clin Invest 1993; 92: 297-302.

102. Langford MP, Chen D, Welbourne TC, Redens TB, Ganley JP Stereo-isomer specific induction of renal cell apoptosis by synthetic muramyl dipeptide (N-acetylmuramyl-L-alanyl-Disoglutamine). Møl Cell Biøchem 2002; 236: 63-73.

103. Chen D, Duggan C, Reden TB, Kooragayala LM, Texada DE, Langfor MP. Calreticulin is a binding protein for muramyl dipeptide and peptidoglycan in $\mathrm{RK}_{13}$ cells. Biechemistry 2004; 43: $11796-11801$.

104. Chen D, Texada DE, Duggan C et al. Surface calreticulin mediates muramyl dipeptide induced apoptosis in $\mathrm{RK}_{13}$ cells. $J$ Biel Chem 2005; 280: 22425-22436.

105. O'Reilly T, Zak O. Enhancement of the effectiveness of antimicrobial therapy by muramyl peptide immunomodulators. Clin Infect Dis 1992; 14: 1100-1109.

106. Vogel FR. Improving vaccine performance with adjuvants. Clin Infect Dis 2000; 30 (Suppl 3): S266-270.

107. Darcissac EC, Bahr GM, Parant MA, Chedid LA, Riveau GJ. Selective induction of CD11a,b,c/CD18 and CD54 expression at the cell surface of human leukocytes by muramyl peptides. Cell Immunol 1996; 169: 294-301

108. Heinzelmann M, Polk Jr HC, Chernobelsky A, Stites TP, Gordon LE. Endotoxin and muramyl dipeptide modulate surface receptor expression on human mononuclear cells. Immun phannacelegy 2000; 48: 117-128.

109. Leclerc C, Juy D, Bourgeois E, Chedid L. In viv $\bullet$ regulation of humoral and cellular immune responses of mice by a synthetic adjuvant, N-acetyl-muramyl-L-alanyl-D-isoglutamine, muramyl dipeptide for MDP. Cell Immunel 1979; 45: 199-206.

110. Dreesman GR, Sanchez Y, Ionescu-Matiu I et al. Antibody to hepatitis B surface antigen after a single inoculation of uncoupled synthetic HBsAg peptides. Nature 1982; 295: 158-160.

111. Morisaki I, Michalek SM, Harmon CC, Torii M, Hamada S, McGhee JR. Effective immunity to dental caries: enhancement of salivary anti-Streptececus mutans antibody responses with oral adjuvants. Infect Immun 1983; 40: 577-591.

112. Masek K, Zaoral M, Jezek J, Straka R. Immunoad juvant activity of synthetic N-acetyl muramyl dipeptide. Experientia 1978; 34: 1363-1364.

113. Saiki I, Fidler IJ. Synergistic activation by recombinant mouse interferon-gamma and muramyl dipeptide of tumoricidal properties in mouse macrophages. J Immunel 1985; 135: 684-688.

114. Souvannavong V, Brown S, Adam A. Muramyl dipeptide (MDP) 
synergizes with interleukin 2 and interleukin 4 to stimulate, respectively, the differentiation and prolif eration of $\mathrm{B}$ cells. Cell Immunel 1990; 126: 106-116

115. Takada H. Enhancement of endotoxin activity by muramyldipeptide. $J$ Endetexin Res 2002; 8: 337-342

116. Takada H, Galanos C. Enhancement of endotox in lethality and generation of anaphylactoid reactions by lipopolysaccharides in muramyl-dipeptide-treated mice. Infect Immun 1987; 55: 409-413.

117. Bloksma N, Hofhuis FM, Willers JM. Muramyl dipeptide is a powerful potentiator of the antitumor action of various tumornecrotizing agents. Cancer Immunol Immun॰ther 1984; 17: $154-159$

118. TakadaH, Hirai H, Fujiwara T, Koga T, Ogawa T, Hamada S. Bacteroides lipopolysaccharides (LPS) induce anaphylactoid and lethal reactions in LPS-responsive and -nonresponsive mice primed with muramyl dipeptide. J Infect Dis 1990; 162 $428-434$

119. Takada H, Kawabata Y, Kawata S, Kusumoto S. Stuctural characteristics of peptidoglycan fragments required to prime mice for induction of anaphylactoid reactions by lipopolysaccharides. Infect Immun 1996; 64: 657-659.

120. Kobayashi KS, Chamaillard M, Ogura Y et al. Nod2-dependent regulation of innate and adaptive immunity in the intestinal tract Science 2005; 307: 731-734.

121. Endo Y, Shibazaki M, Nakamura M, Takada H. Contrasting effects of lipopolysaccharides (endotoxins) from oral blackpigmented bacteria and Enterobacteriaceae on platelets, a major source of serotonin, and on histamine-f orming enzyme in mice. $J$ Infect Dis 1997; 175: :1404-1412.

122. Kawabata Y, Yang TS, Yokochi TT et al. Complement system is involved in anaphylactoid reaction induced by lipopolysaccharides in muramyldipeptide-treated mice. Shock 2000; 14: 572-577.

123. Ohba M, Shibazaki M, Sasano T, Inoue M, TakadaH, Endo Y. Platelet responses and anaphylaxis-like shock induce in mice by intravenous injection of whole cells of oral streptococci. Oral Microbiel Immunel 2004; 19: 26-30.

124. Jorgensen PF, Wang JE, Almlof M et al. Peptidoglycan and lipoteichoic acid modify monocyte phenotype in human whole blood. Clin Diagn Lab Immunel 2001; 8: 515-521.

125. TsuchidaK, Takemoto Y, Yamagami S et al. Detection of peptidoglycan and endotoxin in dialysate, using silkworm larvae plasma and Limulus amebocyte lysate methods. Nephron 1997; 75: $438-443$

126. Netea MG, Ferwerda G, de Jong DJ et al. Nucleotide-binding oligomerization domain- 2 modulates specif ic TLR path ways for the induction of cytokine release. J Immunel 2005; 174 : 6518-6523.

127. Vermeulen MW, David JR, Remold HG. Differential mRNA responses in human macrophages activated by interf eron-gamma and muramyl dipeptide. J Immunel 1987; 139: 7-9.

128. Daemen T, Veninga A, Roerdink FH, Scherph of GL. In vitro activation of rat liver macrophages to tumoricidal activity by free or liposome-encapsulated muramyl dipeptide. Cancer Res 1986; 46: $4330-4335$

129. Beutler E, Gelbart T, West C. Synergy between TLR2 and TLR4: a saf ety mechanism. Bløed Cells Mol Dis 2001; 27: 728-730.

130. Langhans W, Balkowski G, Savoldelli D. Differential feeding responses to bacterial lipopolysaccharide and muramyl dipeptide. Am J Physiel 1991; 261: R659-664.

131. Flak TA, Heiss LN, Engle JT, Goldman WE. Synergistic epithelial responses to endotoxin and a naturally occurring muramyl peptide. Infect Immun 2000; 68: 1235-1242.

132. Uehara A, Yang S, Fujimoto Yet al. Muramyldipeptide and diaminopimelic acid-containing desnuramylpeptides in combination with chemically synthesized Toll-like receptor agonists synergistically induced production of interleukin- 8 in a NOD 2- and NOD1-dependent manner, respectively, in human monocytic cells in culture. Cell Microbiel 2005; 7: :53-61.

133. Schröder NW, Morath S, Alex ander C et al. Lipoteichoic acid (LTA) of Streptececcus pneumeniae and Staphylececcus aureus activates immune cells via Toll-like receptor (TLR)-2, lipopolysaccharide-binding protein (LBP) and CD14 while TLR-4 and MD- 2 are not involved. J Biol Chem 2003; 278: 15587-15594.

134. Kengatharan KM, De Kimpe S, Robson C, Foster SJ, Thiemermann C.Mechanism of Gram-positive shock: identification of peptidoglycan and lipoteichoic acid moieties essential in the ind iction of nitric oxide synthase, shock, and multiple organ failure. JExp Med 1998; 188: :305-315.

135. van Heel DA, Ghosh S, Butler M et al. Muramyl dipeptide and Toll-like receptor sensitivity in NOD2-associated Crohn's disease. Lancet 2005; 365: 1794-1796.

136. Masek K, Petrovicky P. Morphological and pharmacological evidence for the existence of brain regulatory circuits in the immune response. Int J Immun phannacel 1997; 19: 507-510.

137. Silverman DH, Wu H, KarnovskyML. Muramyl peptides and serotonin interact at specific binding sites on macrophages and enhance superoxide release. Biøchem Biøphys Res Cømmun 1985; 131: 1160-1167.

138. Sevcik J, Masek K. The interaction of immunomodulatory muramyl dipeptide with peripheral 5-HT receptors: overview of the current state. Int J Immun॰ pharmacel 1999; 21: 227-232.

139. Sevcik J, Ruzicka V, Slansky J, Masek K. MDP and 5-HT receptors. Does MDP interact with 5-HT(7) receptors? Int $J$ Immun• phannacel 2000; 22: 587-595.

140. Sevcik J, Ruicka V, Slainsky J, Masek K. Muramyl dipeptide (MDP) and 5-HT receptors. Neuroimmunomodulatory effects of MDP are probably not mediated through $5-\mathrm{HT}_{4}$ or $5-\mathrm{HT}_{1 \mathrm{~A}}$ receptors. Immun pharmacel Immunøtexicel 2002; 24: 43-53.

141. Muhvic, D, El-Samalouti V, Flad HD, Radosevic-Stasic B, RukavinaD. The involvement of CD14 in the activation of human monocytes by peptidoglycan monomers. Mediaters Inflamm 2001; 10: : 155-162.

142. Weidemann B, Schletter J, Dziarski R et al. Specific binding of soluble peptidoglycan and muramyldipeptide to CD14 on human monocytes. Infect Immun 1997; 65: 858-864.

143. Asai Y, Ohyama Y, Gen K, Ogawa T. Bacterial fimbriae and their peptides activate human gingival epithelial cells through Toll-like receptor 2. Infect Immun 2001; 69: 7387-7395.

144. Hatakeyama J, Tamai R, Sugiyama A, Akashi S, Sugawara S, Takada $\mathrm{H}$. Contrasting responses of human gingival and periodontal ligament fibroblasts to bacterial cell-surface components through the CD14/Toll-like receptor system. Oral Microbiel Immunel 2003; 18: 14-23.

145. Vidal VF, Casteran N, Riendeau CJet al. Macrophage stimulation with Murabutide, an HIV-suppressive muramyl peptide derivative, selectively activates ex tracellular signal-regulated kinases 1 and 2 , C/EBPbeta and STAT1: role of CD14 and Toll-likereceptors 2 and 4. EurJImmunol 2001; 31: 1962-1971.

146. Dziarski R, Tapping RI, Tobias PS. Binding of bacterial peptidoglycan to CD14.J Bi॰l Chem 1998; 273: 8680-8690.

147. Yoshimura A, TakadaH, Kaneko T, Kato I, GolenbockD, Hara Y. Structural requirements of muramylpeptides for induction of Toll-like receptor 2-mediate NF-kappaB activation in $\mathrm{CHO}$ cells. $J$ Endotexin Res 2000; 6: 407-410.

148. Morr M, Takeuchi O, Akira S, Simon MM, Muhlradt PF Differential recognition of structural details of bacterial lipopeptides by Toll-like receptors. Eur J Immunol 2002; 32 : 3337-3347.

149. Buwitt-Beckmann U, Heine H, Wiesmuller KH et al. Toll-like receptor 6 -independent signaling by diacylated lipopeptides. Eur $J$ Immunel 2005; 35::282-289. 
150. Inohara N, Ogura Y, Fontalba A et al. Host recognition of bacterial muramyl dipeptide mediated through NOD2. Implications for Crohn's disease. J Biøl Chem 2003; 278: 5509-5512.

151. Staskawicz BJ, Mudgett MB, Dangl J, Galan JE. Common and contrasting themes of plant and animal diseases. Science 2001; 292: :2285-2289.

152. Inohara N, Ogura Y, Chen FF, Muto A, Nunez G. Human Nod1 confers responsiveness to bacterial lipopolysaccharides. $J$ Biøl Chem 2001; 276: :2551-2554.

153. Girardin SE, Boneca IG, Cameiro LA etal. Nodl detects a unique muropeptide from Gram-negative bacterial peptidoglycan Science 2003; 300: 1584-1587.

154. Bertin J, Nir WJ, Fischer CM etal. Human CARD4 protein is a novel CED-4/Apaf-1 cell death family member that activates NFkappaB. J Bi॰l Chem 1999; 274: 12955-12958.

155. Inohara N, Koseki T, del Peso L et al. Nod1, an Apaf-1-like activator of caspase- 9 and nuclear factor-kappaB. J Biel Chem 1999; 274: 14560-14567.

156. Carneiro LA, Travassos LH, Philpott DJ. Innate immune recognition of microbes through Nod 1 and Nod2: implications for disease. Micrøbes Infect 2004; 6: 609-616.

157. Girardin SE, Travassos LH, Herve Met al. Peptidoglycan molecular requirements allowing detection by Nodl and Nod2. $J$ Biøl Chem 2003; 278: 41702-41708.

158. Gutierrez O, Pipaon C, Inohara Net al. Induction of Nod 2 in myelomonocytic and intestinal epithelial cells via nuclear factorkappa B activation. $J$ Biel Chem 2002; 277: 41701-41705.

159. Ogura Y, Lala S, Xin W et al. Expression of NOD2 in Paneth cells: a possible link to Crohn's ileitis. Gut 2003; 52: 1591-1597.

160. Lala S, Ogura Y, Osborne C et al. Crohn's disease and the NOD2 gene: a role for Paneth cells. Gastrøenterolegy 2003; 125: 47-57.

161. Abreu MT, Fukata M, Arditi M. TLR signaling in the gut in health and disease. $J$ Immunel 2005; 174: :4453-4460.

162. Berrebi D, Maudinas R, Hugot JP et al. Card 15 gene overexpression in mononuclear and epithelial cells of the inflamed Crohn's disease colon. Gut 2003; 52: :840-846.

163. Maeda S, Hsu LC, Liu Het al. Nod 2 mutation in Crohn's disease potentiates NF-kappaB activity and IL-1 beta processing. Science 2005; 307: :734-738.
164. Ogura Y, Bonen DK, Inohara N et al. A frameshift mutation in NOD2 associated with susceptibility to Crohn's disease. Nature 2001; 411: :603-606.

165. Hugot JP, Chamaillard M, Zouali $\mathrm{H}$ et al. Association of NOD2 leucine-rich repeat variants with susceptibility to Crohn's disease. Nat ure 2001; 411: 599-603.

166.Li J, Moran T, Swanson E et al. Regulation of IL-8 andIL-1beta expression in Crohn's disease associated NOD2/CARD15 mutations. Hum Mel Genet 2004; 13: 1715-1725.

167. Girardin SE, Hugot JP, Sansonetti PJ. Lessons from Nod2 studies: towards a link between Crohn's disease and bacterial sensing. Trends Immun $\bullet$ 2003; 24: 652-658.

168. Watanabe T, Kitani A, Murray PJ, Strober W. NOD2 is a negative regulator of Toll-like receptor 2-mediated Thelper type 1 responses. Nat Immunel 2004; 5: 800-808.

169. Netea MG, Kullberg BJ, de Jong DJ et al. NOD2 mediates antiinflammatory signals induced by TLR2 ligands: implications for Crohn's disease. Eur J Immunel 2004; 34: 2052-2059.

170. Cossart P, Sansonetti PJ. Bacterial invasion: the paradigms of enteroinvasive pathogens. Science 2004; 304: :242-248.

171. Girardin SE, Toumebize R, Mavris Met al. CARD4/Nodl mediates NF-kappaB and JNK activation by invasive Shigella flexneri. EMB Repert 2001; 2: 736-742.

172. Opitz B, Puschel A, Schmeck B et al. Nucleotide-binding oligomerization domain proteins are innate immune receptors for intemalized Streptececcus pneumeniae. J Bial Chem 2004; 279 . 36426-36432.

173. Hisamatsu T, Suzuki M, Reinecker HC, Nadeau WJ, McCormick BA, Podolsky DK. CARD15/NOD2 functions as an antibacterial factor in human intestinal epithelial cells. Gastroenterolegy 2003; 124: 993-1000.

174. Kim JG, Lee SJ, Kagnoff MF. Nod1 is a essential signal transducer in intestinal epithelial cells infected with bacteria that avoid recognition by Toll-like receptors. Infect Immun 2004; 72 : 1487-1495.

175. Viala J, Chaput C, Boneca IG et al. Nod1 responds to peptidoglycan delivered by the Helicebacter pyleri cag pathogenicity island. Nat Immunel 2004; 5: 1166-1174. 